University of Louisville

ThinkIR: The University of Louisville's Institutional Repository

Electronic Theses and Dissertations

$5-2020$

\title{
Functionalizing nanoparticles with CafA protein to target BAR peptide for oral delivery applications.
}

Hetal Desai

University of Louisville

Follow this and additional works at: https://ir.library.louisville.edu/etd

Part of the Oral Biology and Oral Pathology Commons

\section{Recommended Citation}

Desai, Hetal, "Functionalizing nanoparticles with CafA protein to target BAR peptide for oral delivery applications." (2020). Electronic Theses and Dissertations. Paper 3460.

https://doi.org/10.18297/etd/3460

This Master's Thesis is brought to you for free and open access by ThinkIR: The University of Louisville's Institutional Repository. It has been accepted for inclusion in Electronic Theses and Dissertations by an authorized administrator of ThinkIR: The University of Louisville's Institutional Repository. This title appears here courtesy of the author, who has retained all other copyrights. For more information, please contact thinkir@louisville.edu. 


\title{
FUNCTIONALIZING NANOPARTICLES WITH CAFA PROTEIN \\ TO TARGET BAR PEPTIDE FOR ORAL DELIVERY
}

APPLICATIONS

\author{
By \\ Hetal Desai
}

D.D.S., University of California, Los Angeles, 2011

\begin{abstract}
A Thesis
Submitted to the Faculty of the

School of Dentistry of the University of Louisville in Partial Fulfillment of the Requirements

for the Degree of
\end{abstract}

Master of Science

in Oral Biology

Department of Oral Immunology and Infectious Disease

School of Dentistry

University of Louisville

Louisville, KY

May 2020 


\section{Copyright 2020 by Hetal Desai All Rights Reserved}



FUNCTIONALIZING NANOPARTICLES WITH CAFA PROTEIN

TO TARGET BAR PEPTIDE FOR ORAL DELIVERY

APPLICATIONS

By
Hetal Desai

D.D.S., University of California, Los Angeles, 2011

Thesis Approved on

May 1, 2020

By the following Thesis Committee:

Dr. Donald R. Demuth, Ph.D.

Thesis Director

Dr. Jill M. Steinbach-Rankins, Ph.D.

Co- Mentor

Dr. David Scott, Ph.D. 


\section{ACKNOWLEDGEMENTS}

First and foremost, I would like to express my sincerest gratitude to my mentors Dr.

Demuth and Dr. Steinbach for giving me the opportunity to work in their labs and providing me with excellent guidance and invaluable insights throughout the duration of my training. I would also like to thank my committee member Dr. Scott for his encouragement and suggestions during the writing of this thesis.

I would like to convey my heartfelt gratitude to Dr. Pisano for her relentless support throughout the two years. I have enjoyed our conversations over umpteen cups of coffee and am deeply appreciative of your advice with regards to career choices and life in general.

I would like to thank my family for believing in me and constantly encouraging me to pursue a path of my liking, albeit unconventional.

Last but not the least, I would like to thank Julie Tan and Rocky for always taking the time to help me troubleshoot, brainstorm ideas to conduct my experiments more efficiently and most importantly for all the laughs at the end of unproductive days, which made dealing with failures a lot easier.

A special note of thanks to my colleagues, Rohit- my tech support, graphic design consultant and study partner rolled into one and Mina, for being a great listener. 


\section{ABSTRACT}

\section{FUNCTIONALIZING NANOPARTICLES WITH CAFA PROTEIN} TO TARGET BAR PEPTIDE FOR ORAL DELIVERY

\section{APPLICATIONS}

$$
\text { May 1, } 2020
$$

Background: Porphyromonas gingivalis adherence to Streptococcus gordonii may be important for $P$. gingivalis colonization in the oral cavity. Nanoparticles encapsulating synthetic peptide BAR (BAR-NPs) inhibit $P$. gingivalis adherence more potently than free BAR. However, BAR-NPs would exhibit low retention in an open flow environment.

Hypothesis: Targeting BAR-NPs to the streptococcal surface using CafA protein will enhance their efficacy.

Methods: CafA-modified NPs encapsulating BAR were synthesized using double emulsion approach. Surface binding and retention, and release kinetics of BAR 
from CafA-modified NPs was assessed. Functional inhibition assays were performed using dual a species biofilm.

Results: CafA-modified NPs demonstrated specificity of adhesion, remained bound to $S$. gordonii surfaces and released inhibitory concentrations of BAR for over 8hr. CafA-modified NPs inhibited P. gingivalis adherence to $S$. gordonii potently for over $8 \mathrm{hr}$.

Conclusions: CafA-modified NPs represent a delivery vehicle that targets BAR to preferred niches of $P$. gingivalis in the oral cavity. 


\section{TABLE OF CONTENTS}

\section{PAGE}

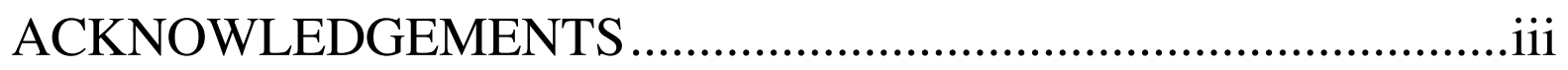

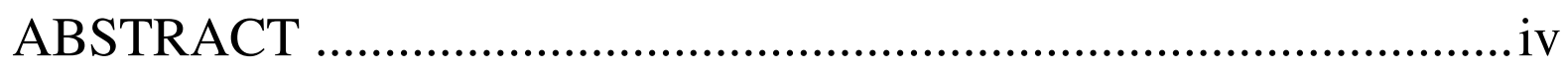

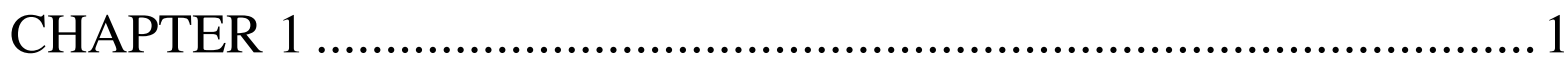

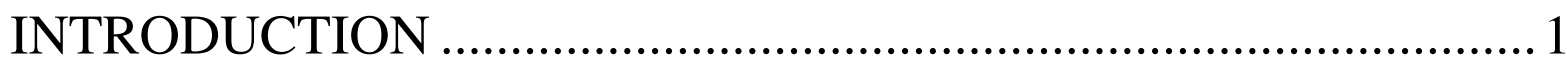

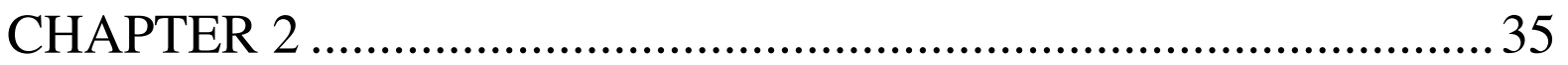

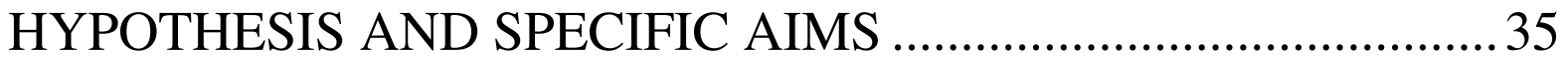

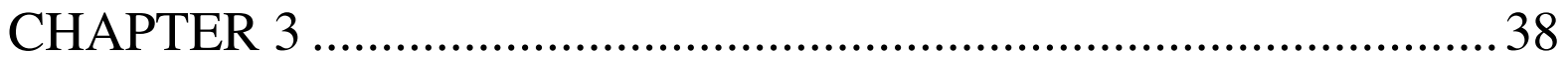

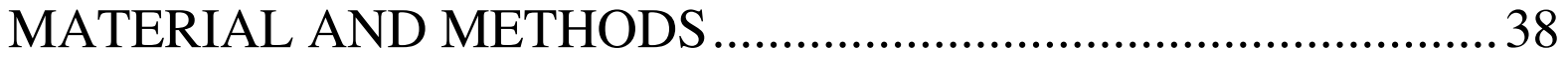

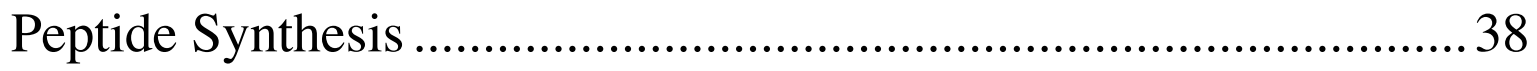

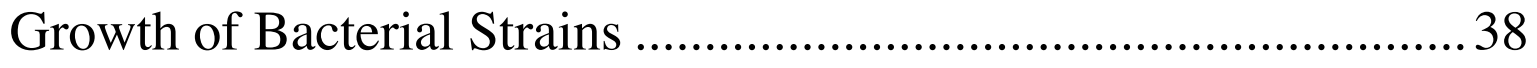

CAfA expression and purification ................................................... 39 
Conjugation of CafA protein with Palmitic acid (CafA-Palmitate Synthesis)

Synthesis of CafA-modified nanoparticles

Synthesis of CafA-modified NPs encapsulating C6/F-BAR/BAR.41

NP Characterization: NP morphology and size .44

Quantification of Surface Density of CafA 44

Loading and release kinetics of BAR peptide from unmodified and

CafA-modified NPs 44

Determination of functionality of surface modification 45

CafA-modified NP-mediated inhibition of P. gingivalis adherence to streptococci .48

CHAPTER 4

RESULTS

NP Characterization: NP morphology and size

Quantification of ligand surface density .53 
Loading and release kinetics of BAR peptide from unmodified and

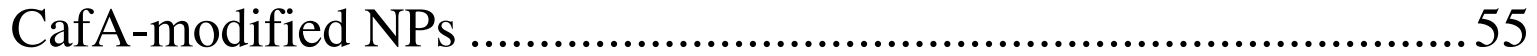

Determination of functionality of surface modification ..................57

Duration of retention of CafA-modified C6 NPs .........................57

Specificity of adhesion of CafA-modified C6 NPs .....................59

CafA-modified NP-mediated Inhibition of P. gingivalis adherence

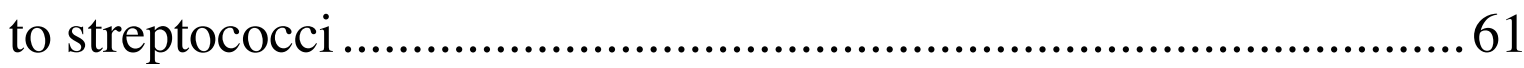

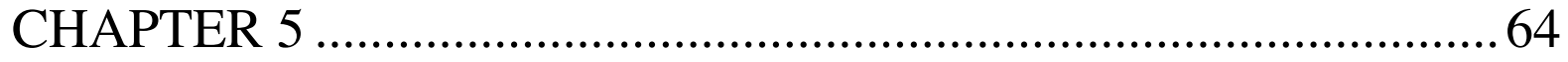

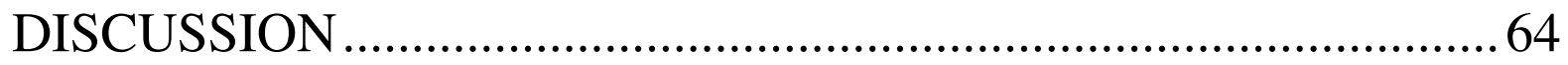

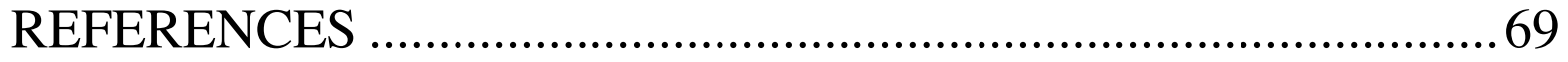

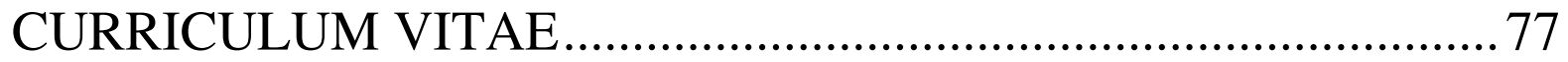




\section{LIST OF FIGURES}

FIGURE

PAGE

Figure 1: Schematic of plaque development and anti-biofilm strategies.......5

Figure 2: Schematic of mechanism of quorum sensing in bacteria..................11

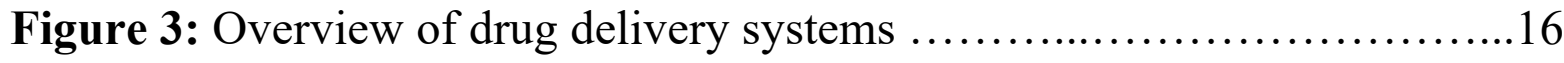

Figure 4: Considerations for development of actively targeted nanoparticles..22

Figure 5: Schematic of $P$. gingivalis $-S$. gordonii interaction...............26

Figure 6: Schematic of $P$. gingivalis $-S$. gordii signalling mechanism.....30,31

Figure 7: Schematic of type 2 fimbriae of $A$. oris......................... 34

Figure 8: Schematic representation of nanoparticles and targeting strategy.....37

Figure 9: Schematic representation of nanoparticle synthesis ...............43

Figure 10: Schematic of duration of retention assay .......................47

Figure 11: Schematic of functional inhibition assay.......................50

Figure 12: SEM images of unmodified and Caf-modified NPs...............52

Figure 13: Quantification of surface ligands ...........................54 
Figure 14: Release kinetics of BAR peptide from unmodified and CafA-modified NPs.....................................................56

Figure 15: Duration of retention of CafA-modified NPs on S. gordonii cells...58

Figure 16: Specificity of adhesion of CafA-modified NPs.................60

Figure 17: Functional inhibition assay using dual species biofilm............62 


\section{CHAPTER 1}

\section{INTRODUCTION}

Periodontitis is the chronic inflammation of tooth-supporting structures, which begins as gingivitis and progressively leads to the destruction of periodontal ligament and alveolar bone. From 2009 to 2012, 46\% of adults (age > 30 years) in the United States, were diagnosed with periodontal diseases. Of these, 8.9\% had advanced periodontitis. Domestically, over 14 billion dollars are spent annually towards the prevention and treatment of periodontal diseases [1]. Periodontal disease is the major cause of tooth loss after the age of 30 and has been associated with systemic diseases, such as cardiovascular diseases, type 2 diabetes mellitus, low birth weights, premature labor and osteoporosis [2]. Periodontitis is caused by the interplay of host susceptibility and changes in the normal microbiota of dental plaque [3].

\section{Role of biofilm in periodontal disease}

Periodontal disease is a biofilm-mediated infection. Biofilms consist of a consortium of organisms that are embedded in a matrix containing extracellular polymeric substances (EPS). As the bacterial colonies in the biofilm grow, the biofilm develops "emergent properties" which differ from those of organisms in the planktonic phase [4]. These properties protect the biofilm and render them resilient to minor environmental alterations. However, environmental alterations beyond a threshold could prompt competitive overgrowth of certain microorganisms, leading to dysbiosis and disease [5]. Gaining a thorough understanding of the mechanism of biofilm formation, its properties, and disease etiology will aid in developing effective therapeutics for periodontal diseases. 


\section{Formation of dental plaque}

Dental plaque is a highly complex biofilm consisting of a diverse bacterial community and their products [6]. It forms via a series of specific, sequential molecular interactions between bacteria and host surfaces that ultimately result in the development of a structurally and functionally organized heterogenous microbial community [7].

\section{Stages of plaque formation:}

\section{(i) Initial Adhesion}

The formation of dental plaque begins with the developpment of acquired pellicle on the tooth enamel. The acquired pellicle is a thin coating formed by the adsorption of proteins and other macromolecules from the saliva and gingival crevicular fluid on the tooth surface. It is comprised of proline-rich proteins (PRPs), albumin, sialic acid, alpha amylase, and glycoproteins, and provides substrates for attachment to early colonizing bacteria [8]. Streptococci constitute $80 \%$ of these primary colonizers $[9,10]$ and bind to components of the salivary pellicle via adhesins, e.g., antigen I/II protein family, amylase-binding adhesin (AbpA), and serine-rich repeat glycoproteins (Has, GspB) $[8,11,12]$. Actinomyces oris is another primary colonizer and its adherence to the PRPs and statherin of the salivary pellicle is mediated via type 1 fimbriae [13]. Initial adherence of the bacteria to the tooth surface is a crucial event in plaque development which prevents the organisms from being washed away by mechanical shearing forces of salivary fluid flow and tongue movement [14].

\section{(ii) Bacterial Coaggregation and Biofilm Maturation}

After initial adherence, the plaque evolves to contain additional species of bacteria, primarily consisting of gram-negative rods. Biofilm formation and growth occurs by the adherence of secondary colonizers to already attached bacterial cells and their metabolic products $[14,15]$. 
Specific interspecies bacterial adhesion is termed coaggregation and leads to an increase in the biovolume and complexity of the biofilm [16]. Coaggregation can occur via direct cell-cell interactions mediated by reciprocal adhesin-receptor binding or via multivalent molecules such as mucin and glucans [14]. Bacterial coaggregation promotes microbial interactions by co-locating physiologically relevant organisms in the same milieu, thereby facilitating development of complex nutritional co-operation, gene transfer and cell-cell signalling [5]. In microbial communities, nutritional interdependence develops amongst the residing organisms, where the product of metabolism of one bacterial species becomes the food source for another, resulting in the development of food webs [4]. Furthermore, metabolic pathways drive the order of colonization, whereby different layers of the biofilm are associated with a specific metabolic pathway that results in a functionally-structured community [17]. The close proximity of the cells also facilitates horizontal gene transfer and increases the adaptive ability of the organisms to changing oral environment [18]. Moreover, cell-cell signalling enables bacterial cells to sense and adapt to various environmental stimuli and control the expression of virulence-regulating genes [5].

As the biofilm grows by bacterial coaagregation, the organisms induce the genetic program to promote biofilm formation which facilitates interbacterial agglutination by the formation of a slimy matrix. All microorganisms residing within biofilms are embedded in this matrix containing extracellular polymeric substances (EPS) [19]. The matrix allows the bacteria to adhere to each other and the colonizing surfaces, protects the bacteria from host defenses, enhances the mechanical stability of the biofilm, facilitates communication between bacterial species, and forms chemical/nutrient gradients that create microenvironments within the biofilm which vary widely in $\mathrm{pH}$, oxygen and nutrient availability $[20,21]$. Thus the matrix allows individual bacterial cells to behave as a cohesive multicellular unit, whose properties and 
characteristics collectively differ from those of free-living bacteria. These "emergent properties" of the biofilms make them more conducive to survival in harsher environments [4, 21].

(iii) Biofilm Dispersion

Detachment of cells from the mature biofilm occurs by various processes, e.g., mechanical sloughing, enzymatic degradation of biofilm matrix, and downregulation of genes responsible for matrix production $[15,22]$. The detached cells disperse and can initiate the formation of a new biofilm under favorable conditions [22] .

These details surrounding the process of biofilm formation can provide insights for developing novel, effective strategies to prevent their initial formation (prophylactic approach) and disrupt existing biofilms (therapeutic approach). Treating biofilm-mediated infections poses a special challenge due to the "emergent properties" of the biofilm and the resulting biofilm-mediated resistance $[22,23]$. The effectiveness of antibiotics in treating biofilm-mediated infections is limited due to: (i) compromised penetration of antibiotics through the polysaccharide matrix of the biofilm [24], (ii) increased drug resistance of bacteria in the biofilm versus planktonic state [23], and (iii) reduced/altered cellular activity of bacteria within the biofilm [25]. Some novel anti-biofilm strategies to prevent, weaken or disrupt biofilm formation are illustrated in Figure $1 \mathrm{~B}$. 


\section{(A)}

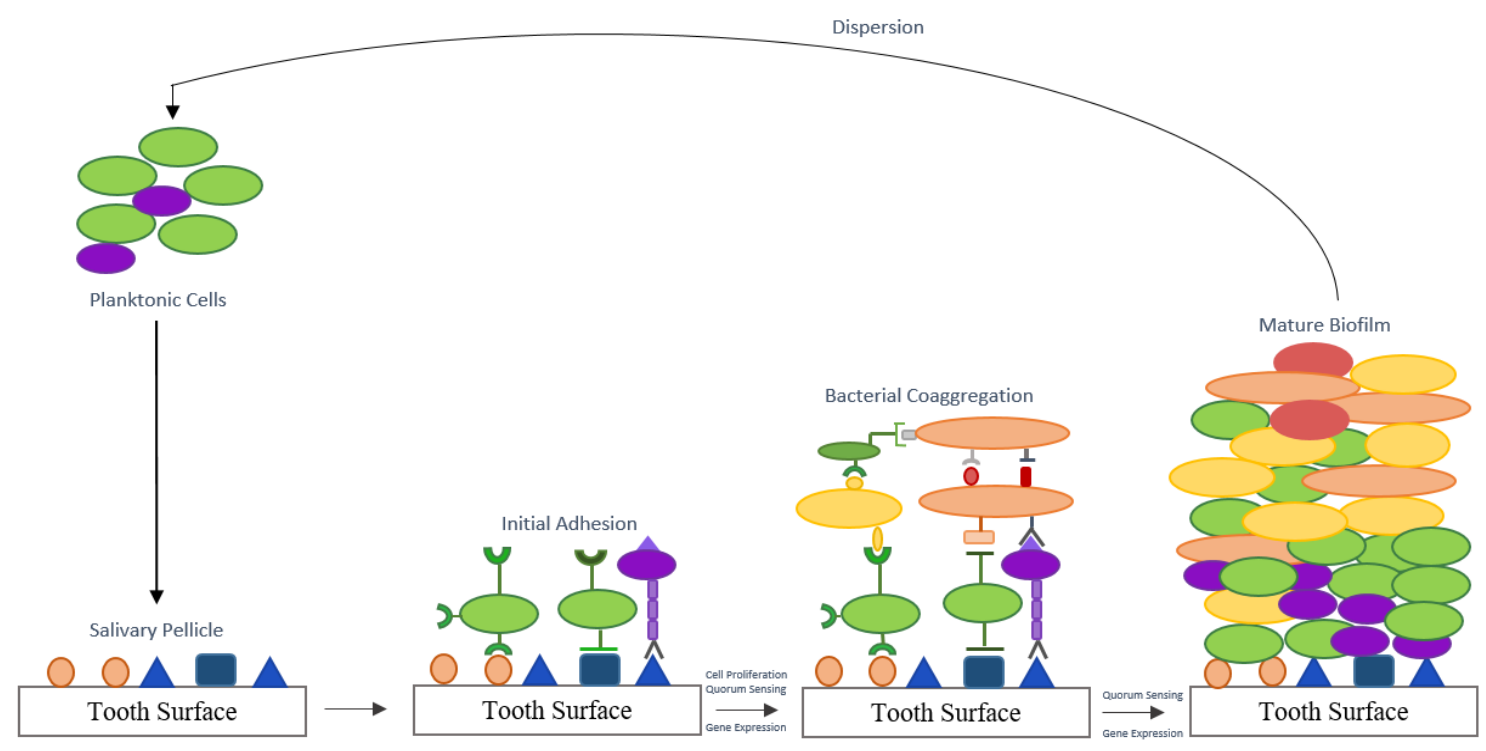

(B)

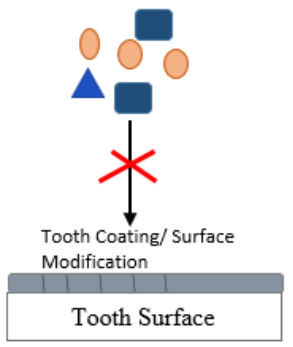

Prevention

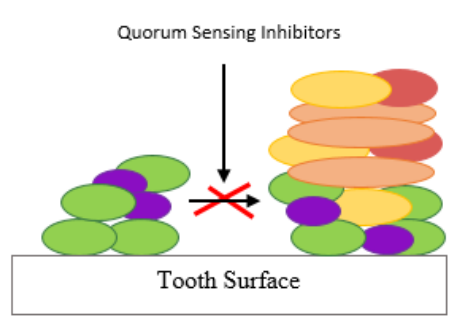

Weakening

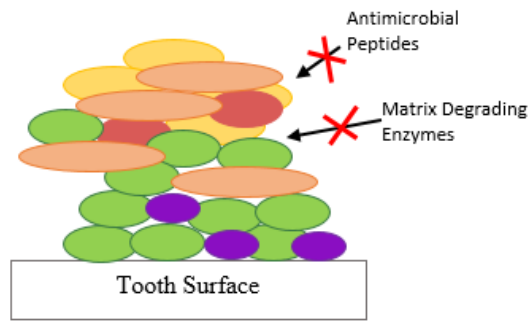

Disruption/Killing

Figure 1: (A) Schematic representation of plaque development. (B) Schematic representation of anti-biofilm strategies (i) coating tooth surfaces with materials to limit initial bacterial adherence and prevent biofilm formation, (ii) interrupting bacterial communication to inhibit development of biofilm properties such as expression of virulence factors, And (iii) disrupting pre-established mature biofilms using "anti-biofilm" peptides and matrix degrading enzymes leading to biofilm destabilization.

Image adapted from: Reffuveille, F., et al., Staphylococcus aureus Biofilms and their Impact on the Medical Field. 2017. 


\section{Etiology of periodontal diseases}

The oral cavity harbors more than 700 bacterial species, some of which have been implicated in the initiation and progression of periodontal diseases. In a study done by Socransky et al., it was observed that periodontal diseases are caused by a consortium of organisms rather than individual pathogens. Moreover, the composition of the microbiome at healthy and diseased periodontal sites varied drastically and certain microbes were repeatedly found clustered together at diseased and healthy sites. Based on these findings, five microbial complexes were defined. Of these, the red complex, which appears later in biofilm development, and comprises three species, Tannerella forsythia, $P$. gingivalis and Treponema denticola, has been considered to be the most pathogenic microbial complex [26-28].

In recent times, metatranscriptome analysis of dental biofilms from sites with active periodontal disease have found that in addition to periodontal pathogens such as Tannerella forsythia and $P$. gingivalis, organisms such as Veillonella parvula, Pseudomonas fluorescens and various streptococci are highly active in transcribing putative virulence factors [29]. These findings have provided evidence for the role of the entire community and not just a few pathogens in causing the disease.

Our current understanding of periodontal disease is based on the Polymicrobial Synergy and Dysbiosis model, which proposes that periodontitis is caused by the dysbiosis of the host microbiome, rather than an exogenous pathogen [3]. $P$. gingivalis has been shown to play a key role in inducing dysbiosis by modulating the innate host responses and elevating the virulence of the microbiome by altering gene expression via interspecies signalling $[3,30]$. 
One of the proposed ways in which $P$. gingivalis modulates host immunity is by initiating C5aR1-TLR2 crosstalk to subvert immune response and promote inflammation [31, 32]. P. gingivalis also suppresses the expression of IL-8 and Th1 chemokines which aid in the recruitment of neutrophils. Transient delays in neutrophil recruitment facilitate initial colonization and allow an increase in the overall microbial load [33]. Uncontrolled bacterial growth disrupts tissue homeostasis and triggers a robust inflammatory response causing tissue breakdown [34]. Under these circumstances, bacterial species that thrive well in an inflammatory environment may outcompete those that do not, resulting in a shift in the host microbiome towards a disease-causing microbiota [3]. Subsequent tissue breakdown yields nutrients (e.g., degraded collagen and heme compounds) which promote the growth of subgingival proteolytic and asaccharolytic bacteria. The gene expression of the microbial community is altered such that genes associated with proteolysis and LPS synthesis are upregulated [35-37], which in turn leads to more inflammation. The dysbiosis-inflammation interplay generates a vicious cycle that drives periodontitis [35, 38, 39].

In summary, $P$. gingivalis may exert a community-wide effect in oral biofilms. It modulates the host immune response to facilitate an overall increase in bacterial load, along with a shift in microbial composition to a more disruptive microbial community. The altered microbiota triggers an uncontrolled inflammatory host response leading to periodontal tissue destruction. $P$. gingivalis also alters the gene expression of the microbiome [40]. Thus, $P$. gingivalis plays a key role in promoting dysbiosis and elevating the virulence of the host microbiome. 


\section{$\underline{\text { Treatment of periodontal diseases }}$}

The conventional treatment of periodontal diseases involves the mechanical removal of plaque/calculus by scaling and root planning, along with the use of antibiotics, administered by systemic or local routes, as adjuncts to prevent its reoccurrence [41-44]. Systemically delivered antibiotics reach the deep periodontal pockets, which are not amenable to professional cleaning, via serum, but require patient compliance and must be administered at a higher dose to be effective [45]. However, chronic, indiscriminate use of antibiotics in the treatment of periodontal disease may lead to adverse side effects such as toxicity, allergies, alteration of gut microflora and increased antimicrobial resistance [46]. Moreover, antibiotic effectiveness in periodontal treatment is limited due to biofilm-mediated resistance and the prevalence of resistant pathogens. In a recent study, $25.49 \%, 23.52 \%$ and $21.56 \%$ of $P$. gingivalis isolates from patients with periodontitis were found to be resistant to amoxicillin, clindamycin and metronidazole, respectively [47].

Organisms such as $P$. gingivalis can also evade host immune surveillance by residing and multiplying within gingival epithelial cells and preventing host cell apoptosis posing a special challenge in the treatment of periodontitis $[48,49]$. At disease sites, $P$. gingivalis have been found to reside within all the layers of the epithelial tissue and in the connective tissue [50]. Commonly used antibiotics such as metronidazole do not readily cross the plasma membrane of cells and therefore are inefficient at killing intracellular organisms. In many cases, after the cessation of antibiotic therapy, these intracellular organisms recolonize periodontal tissue and cause recalcitrant disease. These findings underscore the importance of developing innovative, antimicrobial agents for targeting oral pathogens. 


\section{Why target $P$. gingivalis?}

A longitudinal metatranscriptomic analysis of microbiota from stable to disease-progressing sites showed that only $P$. gingivalis expressed virulence factors at healthy sites, whereas the virulence of $T$. denticola and $T$. forsythia was upregulated after tissue breakdown [29]. This suggests that of all the red complex organisms, $P$. gingivalis likely initiates dysbiosis at healthy sites and other organisms contribute to the acceleration of disease process after homeostasis has already been disrupted [30]. Thus, although $P$. gingivalis is not essential for periodontal diseases, it is an important risk factor in periodontal diseases [30].

Studies have also shown that antibody levels to $P$. gingivalis are consistently higher in patients diagnosed with adult periodontitis [51, 52]. These findings, combined with the role of $P$. gingivalis in inducing host dysbiosis and modulating immunity, makes targeting $P$. gingivalis an effective strategy for developing novel therapies for the prevention and treatment of periodontal diseases.

\section{Current novel treatment strategies targeting $P$. gingivalis}

\section{- Quorum sensing inhibitors (QSI)}

Bacteria in biofilms produce signalling molecules called autoinducers (AI) to communicate with each other. As the density of the bacteria increases, the concentration of Al also increases. By sensing the concentration of $\mathrm{Al}$ in the environment, bacteria gauge their population density, and when the density of the population reaches a certain threshold, it triggers gene expression.. This mechanism of intercellular signalling is known as quorum sensing (QS) (Figure 2). 
Differential gene expression in response to quorum sensing allows bacteria to modulate their phenotypes and behavioral activities when growing in biofilms. At low densities, the bacteria behave as solitary organisms; however, at high densities they develop beneficial traits that facilitate their survival at a community-level. Quorum sensing-dependent activities include biofilm development, expression of virulence factors and bioluminescence [53]. For $P$. gingivalis specifically, the LuxS/AI-2 signalling system is used for quorum sensing and biofilm development $[54,55]$. Therefore, inhibiting this signalling system can potentially weaken biofim formation and suppress the expression of the quorum controlled virulence genes [56]. QSI such as furanone compound [(5Z)-4-bromo-5-(bromomethylene)-2(5H)-furanone] and Dribose inhibit Al-2 and have been shown to inhibit $P$. gingivalis biofilm formation in vitro and mitigate bone loss in a murine model of periodontitis [57]. 

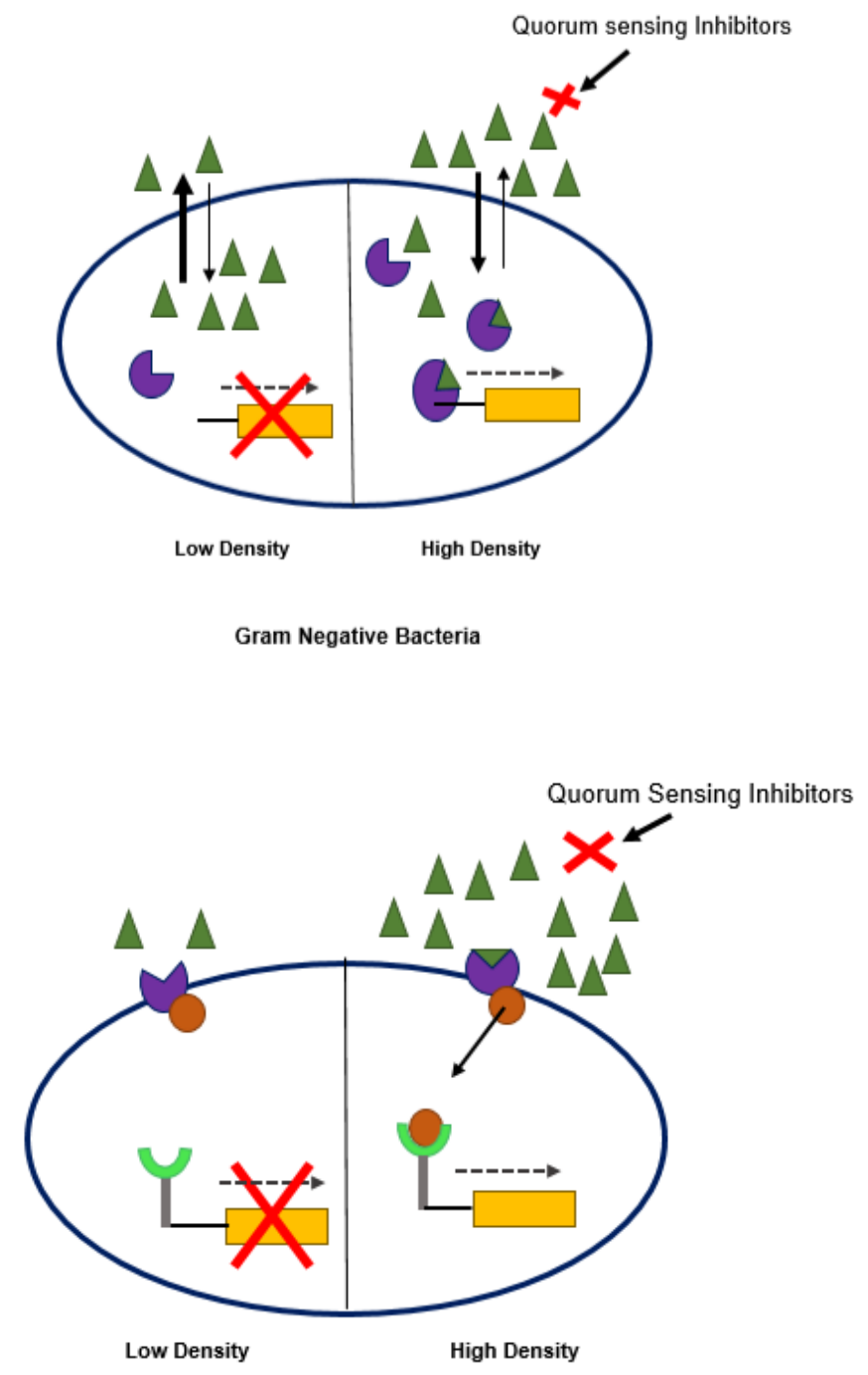

Gram Positive Bacteria

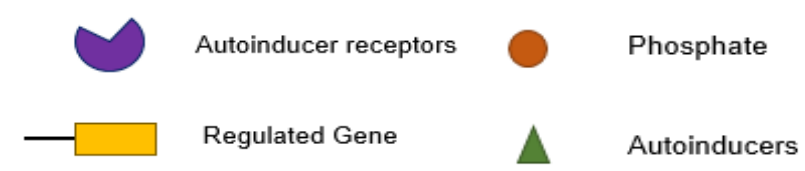

Figure 2: Schematic represention of the mechanism of quorum sensing in bacteria.

Image adapted from: Parray, J., et al., Quorum Sensing: Melody Beneath the Ground. 2018. p. 118. Sankar Ganesh, P. and V. Ravishankar Rai, Alternative Strategies to Regulate Quorum Sensing and Biofilm Formation of Pathogenic Pseudomonas by Quorum Sensing Inhibitors of Diverse Origins, in Biotechnological Applications of Quorum Sensing Inhibitors, V.C. 


\section{- Naturally Derived Compounds}

Plant and marine based compounds such as essential oils, capsaicin, chitosan (crustaceans), andOligoG (oligosaccharide from brown algae alginate) that have the potential to inhibit $P$. gingivalis biofilm formation are currently being investigated for therapeutic use [58]. Presently, a thorough understanding of their precise mechanism of action and cytotoxic potential is lacking, which precludes their use as therapeutic agents [58]. However, some are believed to induce this effect by reducing $P$. gingivalis adherence to gingival epithelial cells, interfering with proteolylic activity of gingipain and inhibiting cytokine secretion. Some naturally derived compounds and their mechanism of action have been listed in Table 1 [59-61].

Table 1: Mechanism of action of some naturally derived compounds.

\begin{tabular}{|c|c|}
\hline $\begin{array}{l}\text { Naturally } \\
\text { Derived } \\
\text { Compound }\end{array}$ & Mechanism of Action \\
\hline $\begin{array}{l}\text { A-type } \\
\text { cranberry } \\
\text { proanthocyanidin }\end{array}$ & $\begin{array}{l}\text { - Anti- P. gingivalis biofilm activity } \\
\text { - Anti-inflammatory (Inhibits IL8 \& chemokine ligand } 5 \text { secretion) } \\
\text { - } \quad \text { Reduces the adherence of } P \text {. gingivalis to oral epithelial cells }\end{array}$ \\
\hline Lacinartin & $\begin{array}{l}\text { - Anti- } P \text {. gingivalis biofilm activity } \\
\text { - Reduces the adherence of } P \text {. gingivalis to oral epithelial cells } \\
\text { - Disrupts pre-formed biofilms }\end{array}$ \\
\hline $\begin{array}{l}\text { Prenylated } \\
\text { flavonoids }\end{array}$ & $\begin{array}{l}\text { - } \quad \text { Inhibits } P \text {. gingivalis biofilm } \\
\text { - } \quad \text { Interferes with Rgp and Kgp gingipain activity }\end{array}$ \\
\hline
\end{tabular}




\section{- Antimicrobial Peptides (AMPs)}

Antimicrobial peptides have been deemed as promising drug candidates since they are conserved and therefore exhibit broad-spectrum activity. AMPs target negatively-charged bacterial cell membranes and kill bacteria by membrane disruption or pore formation [62]. Synthetic AMPs can be engineered to be species-specific with the addition of a targeting moiety $[63,64]$. AMPs also have a lower tendency to induce resistance compared to conventional antibiotics [64]. Some currently studied antimicrobial peptides are discussed below.

- Lactoferrin (LF) is an iron binding glycoprotein and plays an important role in innate immunity. The lipopolysaccharide (LPS) found on the outer membrane of $P$. gingivalis is a crucial virulence factor that mediates its biofilm formation. Lactoferrin binds to LPS and inhibits biofilm formation. Additionally, P. gingivalis has an absolute requirement of iron for its growth and LF, due to its ability to sequester iron, can inhibit its growth [65].

- $\quad$ Nal- $\mathrm{p}-113$ is a cationic AMP which exhibits bactericidal activity by perforating the plasmalemma, resulting in cell death. Moreover, it is resistant to proteolytic degradation. In vitro studies have shown that it is effective in eradicating $P$. gingivalis in the planktonic state and inhibiting subsequent biofilm formation [66].

- BAR peptide is a synthetic peptide derived from a specific region of the streptococcal SspB polypeptide (residues 1167 to 1193) and is comprised of the functional motifs VXXLL and NITVK. BAR peptide blocks the interaction between P. gingivalis and S. gordonii and therefore limits the colonization of $P$. gingivalis and has been shown to reduce virulence in murine model of periodontitis [67]. 


\section{- Small molecules:}

Owing to the high cost of peptide synthesis and the susceptibility of peptides to degradation by proteases [68], small molecules with antimicrobial activity against $P$. gingivalis are being researched for therapeutic potential. For example, BAR peptide consists of lysine residues that are susceptible to Lys-gingipain expressed by $P$. gingivalis. 1,2,3-Triazole-based compounds, formed by joining the synthetic mimics of the functional motifs of BAR peptide (VXXLL and NITVK) by a click-reaction, have been found to be compact, stable and potent inhibitors of $P$. gingivalis - S. gordonii biofilm formation $[69,70]$. Of these compounds, PCPIII-201 was found to inhibit P. gingivalis biofilm formation even in the presence of F. nucleatum, to disrupt pre-established three-species biofilms, and to significantly reduce alveolar bone loss in murine models of periodontitis [71].

\section{Use of nanotechnology in the control of biofilm mediated infection}

In recent times, nanoparticles (NPs) have emerged as promising delivery vehicles to combat biofilm formation due to their unique nanoscale physicochemical properties [72]. Properties such as NP size, shape and surface charge help to facilitate or hinder penetration into biofilms via fluid channels. The self-diffusion coefficient of NPs decreases with the square of the NP radius [73]. For a constant volume, decreasing the size and increasing the aspect ratio enhances the efficacy of the NP [74]. Furthermore, while anionic and neutral quantum dots have been shown to have difficulty penetrating biofilms, cationic quantum dots have been found to widely distribute throughout biofilms. In addition, factors such as hydrophobicity can impact bacterial internalization or localization at the bacterial surface. As one example, cationic quantum dots with hydrophobic terminal groups are more readily internalized by the bacteria relative to hydrophilic quantum dots which remain in the EPS matrix of the biofilm [75]. Hence, manipulation of physical attributes such as size and shape, combined with 
chemical characteristics of surface charge and hydrophobicity, can enhance NP penetration and alter their ability to be internalized by bacteria.

Along with improved biofilm penetration and increased cellular uptake, another advantage of NPs is the reduced likelihood of resistance development since NPs use several mechanisms simultaneously to combat microbes [76]. For instance, chitosan nanoparticles have a positive charge and therefore can associate with negatively-charged bacterial cell walls, increase cell permeability and cause osmotic damage. Additionally, chitosan can bind to DNA in bacterial cells and inhibit mRNA transcription and protein translation. It may also decrease the activity of metalloproteins by chelating metals [77]. Therefore, multiple simultaneous genetic mutationions are required to occur in the same bacterial cell for resistance development. NPs may also be used to overcome existing bacterial resistance mechanisms such as permeability regulation, multidrug efflux pumps and target site mutations [78-80]. Figure 3 depicts some advantages of using nanosized carriers as drug delivery systems over traditional systematic and local routes. A more in-depth description of delivery vehicle options that can be used in oral delivery can be found in review papers by Zupancic, S., et al and Goyal, G., et al. 


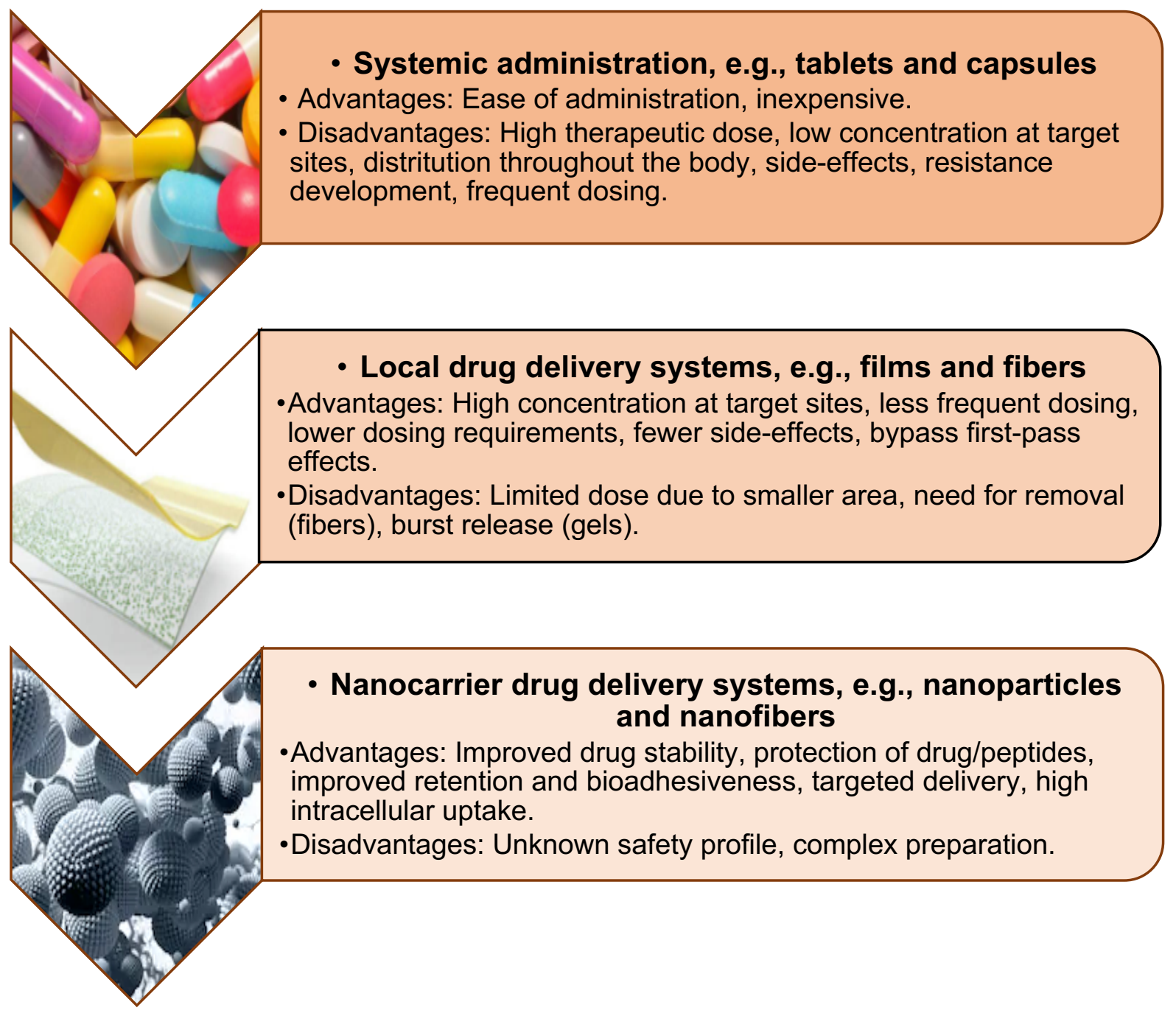

Figure 3: Overview of drug delivery systems.

Image adapted from: Zupancic, S., et al., Contribution of Nanotechnology to Improved

Treatment of Periodontal Disease. Curr Pharm Des, 2015. 21(22): p. 3257-71. 
A wide variety of materials have been used to fabricate nanoparticle delivery vehicles for oral applications, which include metals and metal oxides, such as silver [81]; gold and copper [82, 83]; lipids [84]; and polymers [85]. Metal and metal oxide particles have been used due to their inherent antimicrobial properties [86]; however, there are several concerns regarding the toxicity associated with their accumulation at target sites [87]. Biodegradable materials such are polymers have gained popularity in recent times due to their biocompatibility, reduced side-effects, diverse features (e.g., hydrophilicity, lipophilicity) and ease of modifying their physical properties by changing their chemical structure or by using polymer blends to optimize NP function $[88,89]$. Owing to their ability to be internalized, polymeric NPs can be developed to address special challenges posed by intracellular dwelling organisms such as $P$. gingivalis that can cause recalcitrant disease. Polymersomes encapsulating metronidazole have been shown to penetrate through two-third of the epithelium in $24 \mathrm{hr}$ and reduce intracellular $P$. gingivalis levels significantly relative to free drug, due to their ability to be internalized by the gingival epithelial cells [90]. Polymeric nanoparticle that repond to stimuli have been developed to provide more control over the release of the active agent and diminish undesirable side effects. These NPs demonstrate therapeutic selectivity by responding to stimuli such as shifts in $\mathrm{pH}$, pressure, temperature and oxygen [91]. Horev et al. designed farnesol loaded $\mathrm{pH}$-responsive polymeric nanoparticles to bind avidly to the pellicle and EPS of the biofilm, enhancing drug retention at target sites at physiologic $\mathrm{pH}$. The nanoparticles were tuned to rapidly release the drug when the local $\mathrm{pH}$ became acidic, as would be observed in a cariogenic environment [92].

In addition to the aforementioned features, polymeric nanoparticles offer some special advantages such as the protection and stabilization of drugs/proteins, high drug loading capacity, controlled and sustained drug release, modifiable rate of polymer degradation and drug release. The rate of polmer degradation can be reduced with the use of hydrophobic 
polymers such as polylactic acid (PLA) and polycaprolactone (PCL) which decrease the diffusion of water, whereas, the use of hydrophilic polymer such as polyglycolic acid (PGA) demonstrates the opposite effect. Additionally, the size and surface characteristics of polymeric NPs can also be easily manipulated to promote penetration of NPs, increase residence time at target sites and enable site-specific targeting [93]. Lately, there has been a tremendous interest in developing targeted NPs to improve safety, biodistribution and efficacy of drugs. In vivo, targeting has been shown to increase accumulation and retention of NPs at target sites free drug [94-97]. Moreover, localized release of encapsulated agent from the accumulated NPs at the target sites can enhance the potency of the drug relative to free drug [94-97].

\section{Development of targeted nanoparticles}

Two basic strategies of active and passive targeting have been applied to design NPs that promote site-specific delivery of active agents. Passive targeting relies on the physicochemical properties of the NPs (i.e., size, surface charge, mucoadhesivity) and features of the disease causing agent/disease process (negative charge on bacterial surfaces, leakiness of tumor vasculature) [98]. Passive targeting strategies have involved integrating carboxymethyl cellulose (CMC) [99], polyacrylic acid (Carbopol) [100], polyethylene glycol (PEG) [101, 102], polyvinyl alcohol (PVA) [103] or polyvinyl pyrrolidone (PVP) $[103,104]$ on the surfaces of NPs, which has been shown to improve NP retention and accumulation at target sites. The nanoparticles act as drug depots at target sites and release the active agent at the desired sites in a controlled and sustained manner [105]. Chitosan has been widely used in oral applications, due to its inherent mucoadhesive properties [106].

In comparison, active targeting relies on a biological interaction between ligands on the NP surface and target cell receptors. The use of specific targeting ligands has been shown to 
increase NPs binding efficiency by more than two to four-fold at target sites, due to multivalent interactions [107-109]. Moreover, minimizing non-specific interactions between NPs and nontarget cells helps to reduce indiscriminate distribution of active agents at non-target sites and promotes localized delivery to target sites, enhancing NP efficacy [110, 111].

\section{Polymeric nanoparticles and treatment of periodontal diseases}

Both passively and actively targeted NPs have been developed for use in the treatment of periodontal disease.

\section{Passively targeted NPs}

Chitosan NPs have been extensively used as passively targeted NPs due to their mucoadhesive properties. NPs formulated using thiolated chitosan (TCS)-poly (methacrylic acid) (PMAA) (TCS-PMAA) encapsulating metronidazole benzoate (MET) have been shown to exhibit high mucoadhesiveness due to water uptake from the mucosal tissue by adsorption, swelling and capillary effect, leading to stronger adhesion. These NPs also demonstrated sustained release of MET over $24 \mathrm{hr}$ and improved its oral availability at target sites [112]. In another study, PLGA-lovastatin-chitosan-tetracycline nanoparticles were found to exhibit potent antibacterial activity against $A$. actinomycetemcomitans and $P$. nigrescens in vitro. They also improved alkaline phosphatase activity leading to a significant increase in new bone formation in beagle dogs [113].

\section{Actively targeted NPS}

Actively targeted NPs involve modifying the surfaces of the NPs with biological ligands that promote specific interactions between the ligands on the NP surfaces and target cell receptors. Several biological ligands such as antibodies, aptamers, peptides and small molecules have been used to modify the surfaces of the NPs to improve their binding efficiency on target cells [94, 95]. Often, ligands are directed to exploit endogenous differences between normal and pathological tissues and to direct therapy to classical or diseased target 
site markers. As one example in periodontitis, inflamed gingival epithelial cells express a higher level of the $\beta_{1}$ integrin including $\alpha_{2} \beta_{1}, \alpha_{3} \beta_{1}, \alpha_{5} \beta_{1}$ and $\alpha_{6} \beta_{1}$, relative to normal epithelial cells. Surface modification of NPs with a peptide, RGD, which binds to the $\beta_{1}$ integrin, helps to facilitate NP adherence and retention at periodontal disease sites for a prolonged duration. As such, minocycline-loaded poly(ethylene glycol)-poly(lactic acid) (PEG-PLA) NPs functionalized with RGD peptides demonstrated potent anti-periodontitis activity relative to non-targeted NPs and free minocycline [114]. Additionally, RGD-modified minocycline NPs delivered a higher localized concentration of minocycline to the gingiva and retained the effective concentration for a longer duration, relative to unmodified minocycline NPs [114]. While few studies have employed active targeting approaches for the treatment of periodontal diseases, previous work in our group sought to utilize the targeting capabilities of BAR peptide to improve NP targeting, and thereby enhance potency, via surface-modification. In our

previous work, we developed PLGA nanoparticles functionalized with a synthetic peptide (BAR) $\left(\mathrm{IC}_{50}=0.2 \mu \mathrm{M}\right)$, and showed that BAR-modified NPs are more efficacious and inhibit P.gingivalis adherence to $S$. gordonii more potently relative to free $\mathrm{BAR}\left(\mathrm{IC}_{50}=1.3 \mu \mathrm{M}\right)$ in vitro. In murine models of periodontitis, BAR-modified NPs reduced alveolar bone loss and promoted an anti-inflammatory response by decreasing the expression of IL-17, a proinflammatory cytokine [115].

\section{Considerations for developing actively targeted nanoparticles}

Although active targeting can enhance NP efficacy by improving binding efficiency to target cell receptors, increasing NP residence time at target sites and promoting the localized delivery of active agents, several factors must be considered in the design of optimally functioning actively-targeted nanocarriers. Generally, increasing the surface ligand density improves the receptor binding avidity of surface-modified NPs by promoting multivalent 
interactions. However, several studies have found that NPs with an intermediate ligand density are more efficacious and exhibit higher binding relative to higher ligand density NPs [116-118]. This may be due to steric hindrance that affects receptor accessibility (Figure 4A); increased size of NPs following surface modification, which limits NP diffusion to receptors at target sites; and improper ligand orientation, with high packing density that interferes with ligand functionality $[105,119]$. It has also been found that the addition of surface ligands improves binding efficiency only if the receptors are spaced closely enough together to allow for multiple ligands on the same NP to simultaneously bind to several target cell receptors (Figure 4B) [119]. Furthermore, receptor clustering due to multiple receptor binding on the target cell could result in cell activation, proliferation and other adverse effects [105]. Moreover, surface modification with target ligands may impede the release of the encapsulant. Slower release rates may result in lower available concentrations of the active agent at the target sites and reduced effectiveness of the surface-modified NPs [107]. Therefore, while designing NPs for optimal function, the addition of ligands to enhance binding efficiency must be weighed against its impact on key parameters including encapsulation efficiency, release kinetics of the encapsulant, and intracellular signalling [107]. 
(A)

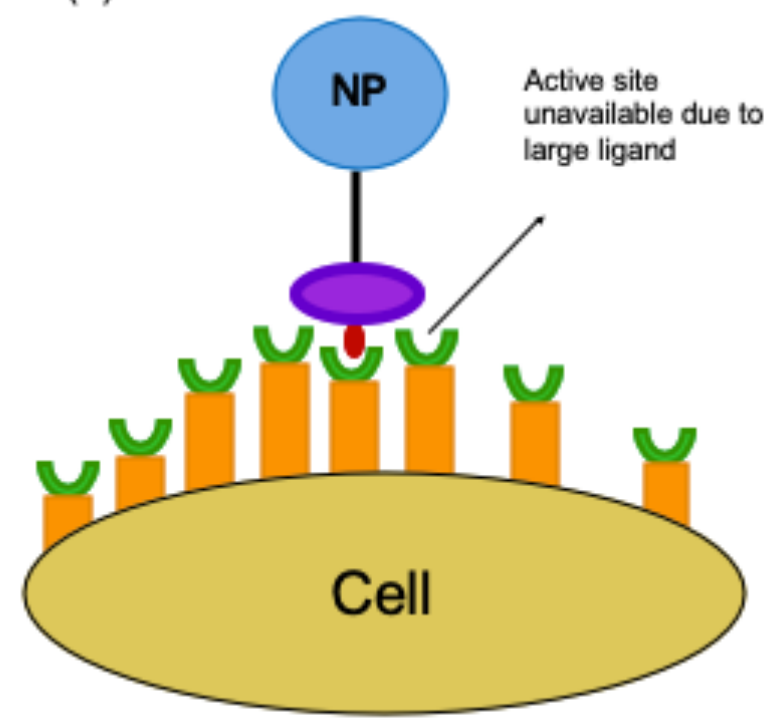

(B)
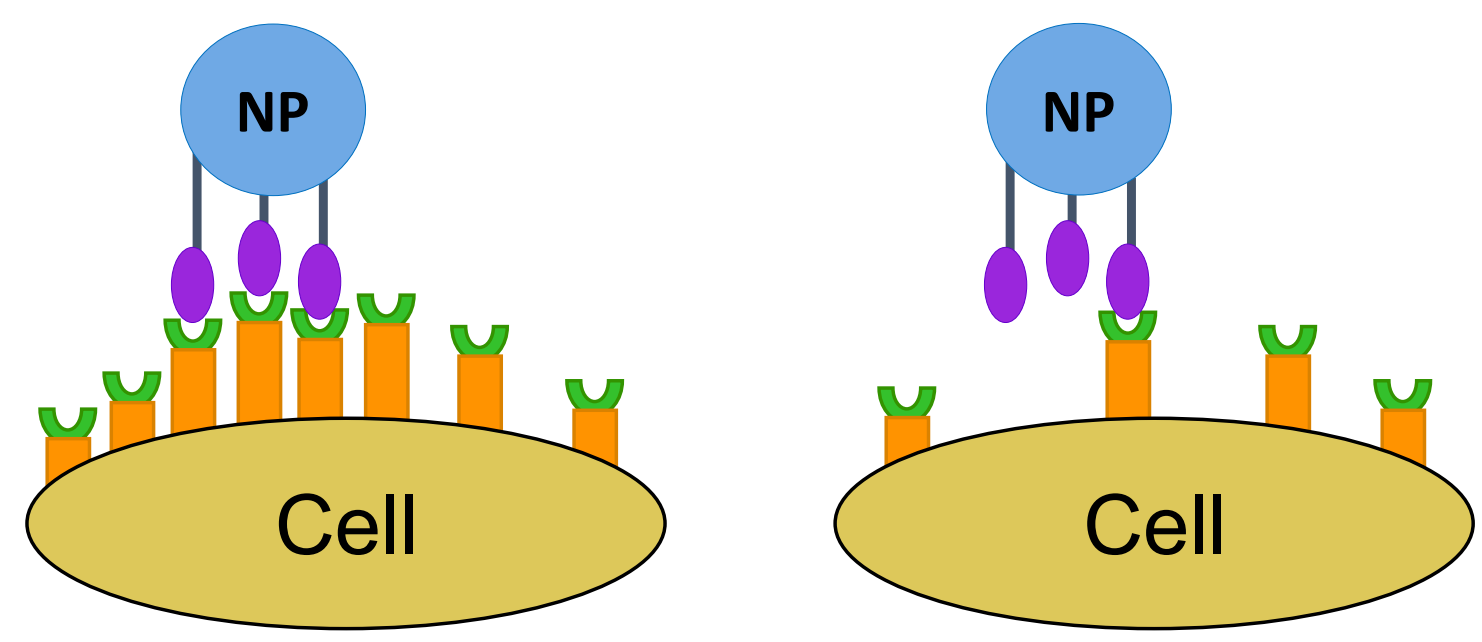

Figure 4: Considerations for developing actively targeted nanoparticles. (A) High ligand density may not always improve NP binding efficiency. One reason may be limited accessibility to receptors on the target cell. (B) Binding efficiency improves only when multiple ligands on the same NP bind to multiple receptors on target cell, promoting multivalent interactions. However, when receptors on target cell are placed further apart and do not allow for multiple ligands on the same NP to bind to them simultaneously, addition of ligands does not improve NP binding efficiency. Figure not drawn to scale. 


\section{BAR peptide}

Oral biofilm formation occurs via sequential, species-specific bacterial coaggregation. One of the bacteria involved in this coaggregation is $P$. gingivalis, a gram-negative, assacharolytic, obligatory anaerobe that resides mainly in the subgingival sulcus [120]. However, the subgingival colonization of $P$. gingivalis is likely to occur only after its initial colonization within the supragingival biofilm. The initial supragingival colonization of $P$. gingivalis is mediated through interactions with certain species of oral streptococci and/or Fusobacterium nucleatum that provide physiologic support to facilitate its survival in the supragingival environment [121]. After its supragingival colonization, $P$. gingivalis disperse and colonize in their preferred niches of the anaerobic subgingival sulcus [120]. Given the downstream events initiated by $P$. gingivalis binding, these initial supragingival interspecies interactions present viable targets for early therapeutic intervention to limit $P$. gingivalis colonization.

One of the primary organisms that promotes the supragingival colonization of $P$. gingivalis is S. gordonii. Adherence of $P$. gingivalis to $S$. gordonii is a multimodal protein-protein interaction that involves both the short and long fimbriae of $P$. gingivalis [122]. FimA, the structural subunit of the major fimbriae, interacts with cell surface glyceraldehyde 3-phosphate dehydrogenase of S. gordonii [123, 124], while Mfa1, the structural subunit of the minor fimbriae, interacts with discrete domains of the streptococcal cell surface protein SspB of the antigen I/II family [125]. The Mfa-SspB interaction is the driving force that mediates interbacterial coaggregation and is essential for the development of $P$. gingivalis biofilms on a streptococcal substratum. SspB polypeptide is 1500 residues in length and consists of seven structural domains that are conserved in all antigen I/II polypeptides. A region encompassing residues 1167 to 1250 promotes the adherence of SspB protein of S. gordonii to $P$. gingivalis [126]. Although virtually 
all oral streptococci express antigen I/II proteins, P. gingivalis selectively adheres to certain species such as S. oralis and S. gordonii but not S. mutans and S. intermedius. Further comparison of the adherence-promoting region of SspB protein of $S$. gordonii to the corresponding region of $S$. mutans antigen $\mathrm{I} / \mathrm{II}$ showed that a protein determinant comprising of 1167 to 1193 was adequate to promote $P$. gingivalis adherence [127]. The recognition of this discrete structural motif of SspB (SspB Adherence Region), that is not conserved in SspA, a related antigen I/II protein of $S$. mutans, accounts for the species specificity of $P$. gingivalis adherence. More specifically, Asn ${ }^{1182}$, Thr ${ }^{1184}$ and Val ${ }^{1185}$ in SspB are not conserved in the SpaP sequence of S. mutans [127].

The synthetic analog of SspB adherence region (BAR), comprised of residues 1167 to 1193 , also potently inhibits Mfa-SspB interaction. It consists of two structural motifs, VXXLL and NITVK (amino acids 1171 to 1180 and 1182 to 1186 , respectively in the full-length antigen I/II protein of $S$. gordonii) which are essential for the interaction of the peptide with Mfa. Additonally, a motif EXXP, upstream of VXXLL, also contributes to the interaction. Analogs of BAR that lack the EXXP motif, exhibit a lower specific activity relative to BAR $[67,128]$. In a study by Daep et al. it was found that $P$. gingivalis bound efficiently to BAR-like peptides with amino acid substitutions at both the non-conserved residues 1182 and 1185 . Substitution of positively-charged amino acids at position 1182 and hydrophobic residues at 1185, further enhanced the activity of the peptide, whereas substitution with acidic residues at position 1182 reduced $P$. gingivalis adherence and no other amino acids were tolerated at position 1185 . These findings suggest that the (i) properties and characteristics of the amino acids occupying these positions were more important, not the specific amino acids, and (ii) Mfa-SspB interaction is driven by both electrostatic and hydrophobic bonding [67]. Substitution of cysteine residues for $\operatorname{Leu}^{1167}$ and Leu ${ }^{1191}$, which yielded a cyclic structurally-constrained 
peptide was found to be a more competitive inhibitor of $P$. gingivalis biofilm formation than BAR peptide, suggesting that the secondary structure and conformation of the peptide is crucial to the function of the peptide. Overall these results suggested that peptides or peptidomimetics with greater specific inhibitory activity than that of BAR can be synthesized. In vivo studies demonstrated that BAR peptide inhibits $P$. gingivalis $-S$. gordonii biofilm formation potently mitigates the bone loss in murine model of periodontitis [129]. 


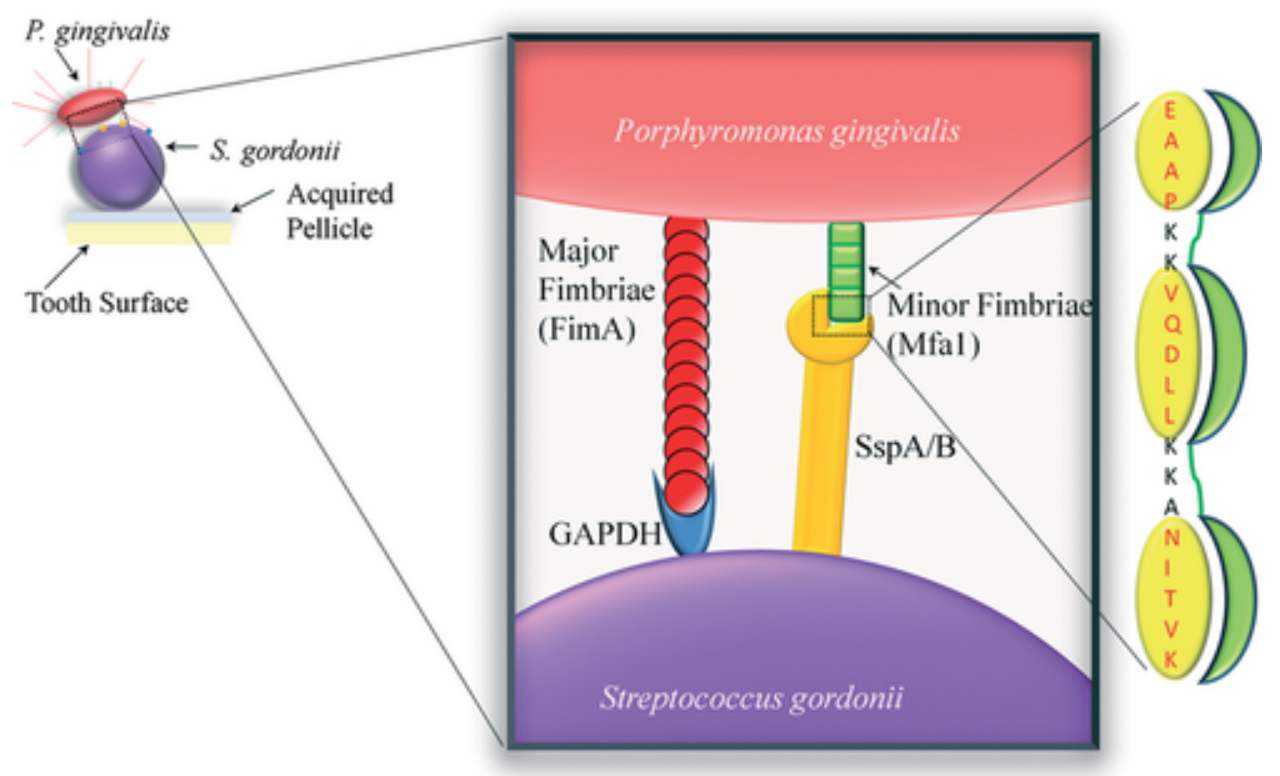

Figure 5: Schematic representation of $P$. gingivalis - S. gordonii interaction. $P$. gingivalis - S. gordonii adhesion is mediated via the interaction of major (fimA) and minor fimbriae (Mfa1) of P. gingivalis and glyceraldehyde 3-phosphate dehydrogenase (GAPDH) and discrete domains on SspA/B (Antigen I/II) adhesin of S. gordonii, respectively. The domains of SspA/B that interact with the minor fimbriae subunit, Mfa1, are highlighted on the right. These domains reside within the $\mathrm{SspA} \underline{\mathrm{B}}$ adherence region $(\mathrm{BAR})$ and are required to promote $P$. gingivalis adherence. $P$. gingivalis does not adhere to organisms lacking the BAR motif in the antigen I/II protein.

Image: Wright, C.J., et al., Microbial interactions in building of communities. Mol Oral Microbiol, 2013. 28(2): p. 83-101. 


\section{$\underline{P . \text { gingivalis }-S \text {. gordonii Interaction (Figure } 6 A \text { and } B \text { ) }}$}

P. gingivalis - S. gordonii aggregation is mutualistic and tightly regulated. P. gingivalis $-S$. gordonii aggregration is regulated by contact-based signalling and through the detection of diffusible mediators such as para-amino benzoic acid ( $p A B A)$. These interactions initially facilitate the formation of heterotypic community and ultimately limit the development of excessive microcolonies to prevent states of depleted nutrition and exposure to elevated levels of oxygen $[130,131]$.

The accumulation of $P$. gingivalis on a substratum of $S$. gordonii is facilitated by increased expression of $m f a 1$ and luxS genes. Increased transcription of $m f a 1$ results in increased expression of fimbrial protein, which in turn primes the organism for colonization, whereas, increased luxS transcription results in elevated levels of $\mathrm{Al}-2$, a quorum signalling molecule that aids in $P$. gingivalis - S. gordonii community development $[125,132]$.

In P. gingivalis, the expression of $m f a 1$ is suppressed through a pathway involving Ltp1 (Low Molecular Weight Tyrosine Phosphatase), which dephosphorylates Ptk1 and indirectly upregulates the transcription of CdhR (Community Development and Hemin Regulator), a negative regulator of luxS and Mfa gene [130].

Following contact with S. gordonii, a streptococci derived contact based signal propogating through Mfa elevates the levels of $L \operatorname{tp} 1$ in $P$. gingivalis. Increased Ltp1 levels, indirectly results in increased CdhR levels, which in turn reduces the transcription of luxS and mfa gene and consequently restrains $P$. gingivalis accumulation on $S$. gordonii. Furthermore, Al-2 is a negative regulator of CdhR. Therefore, reduced levels of luxS/AI-2 further increases $c d h R$ expression which further constrains community development. Thus, reduction of Al-2 levels 
compensates for the loss of contact based signalling due to the reduction of Mfa fimbrial expression and continues to restrain community development [130].

CdhR is a positive regulator of $h m u$ operon involved in hemin uptake and dephosphorylation of gingipain proteases. Increased levels of CdhR increases $h m u$ transcription and in turn elevates the pathogenic potential of the organism [130].

In summary, the activation of Ltp1-CdhR pathway in P. gingivalis via contact-based signalling limits $P$. gingivalis $-S$. gordonii heterotypic community development by downregulating the expression of mfa1 and luxS genes and increases the pathogenicity of $P$. gingivalis by upregulating the expression of $h m u$ gene .

Chorismate-binding enzyme encoded by cbe gene in S. gordonii produces a metabolite 4amino benzoate/para-amino benzoic acid ( $p A B A$ ) which can be released extracellularly (Figure 6a). PABA inactivates Ltp1-CdhR pathway in $P$. gingivalis and upregulates the expression of Mfa1 fimbrial protein. Consequently, the dephosphorylation and inactivation of Ptk1 is reduced. Since Ptk1 activity converges on fimA gene, the level of FimA fimbrial protein is elevated. Therefore, pABA upregulates the expression of both Mfa1 and FimA, priming the organism for coadhesion with S. gordonii and community development. Concomitantly, pABA dimishes the pathogenicity of $P$. gingivalis by reducing the production of extracellular polysaccharides. However, following the aggregation of $P$. gingivalis on S. gordonii, the calming effects of pABA are reduced, most likely due to spatial constraints in the accessibility of pABA and subsequently, the pathogenicity of the $P$. gingivalis $-S$. gordonii community is increased due to the activation of the Ltp1-CdhR pathway via contact based signalling [131]. P. gingivalis - S. gordonii coadhesion and signalling is crucial for development of a dysbiotic microbial community. $P$. gingivalis virulence is increased following coadhesion with 
S. gordonii . Co-infection with both bacterial species causes a greater amount of alveolar bone loss relative to infection with either species alone [129]. Therefore blocking these early interactions could potentially limit the colonization of $P$. gingivalis and reduce the pathogenicity of the subsequent biofilm. 
a

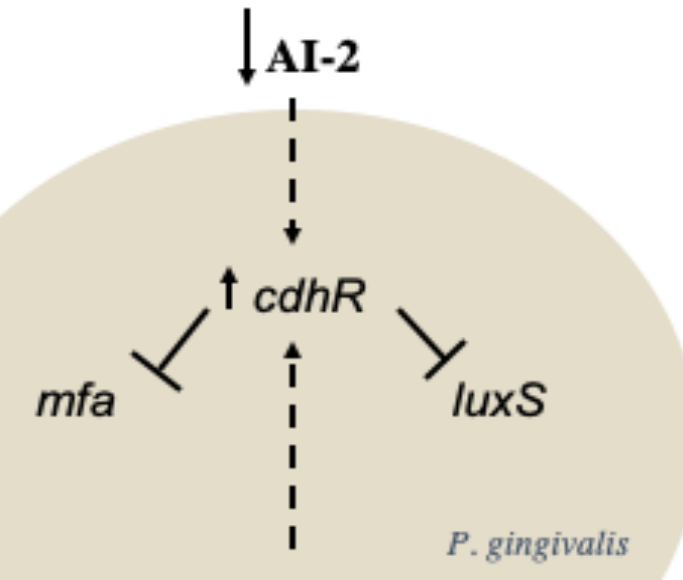

$\uparrow$ Itp1

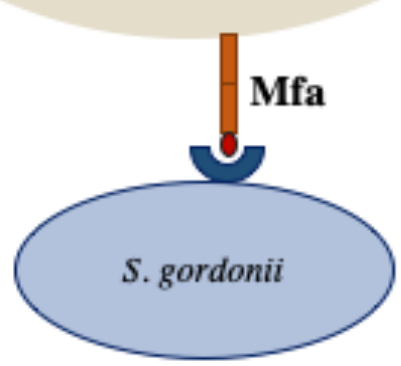

Figure 6a: Schematic representation of $P$. gingivalis - S. gordonii signalling mechanism.

(a) Binding of Mfa1-SspB (contact dependent signalling) increases the levels of Ltp1 and $\operatorname{cdhR}$ (indirectly). Higher levels of cdhR decreases the levels of Mfa and luxS which results in decreased $P$. gingivalis - S. gordonii aggregation. Reduction in the levels of Al-2 further increases the levels of cdhR and limits community development.

Image adapted from : Chawla, A., et al., Community signalling between Streptococcus gordonii and Porphyromonas gingivalis is controlled by the transcriptional regulator $\mathrm{CdhR}$. Mol Microbiol, 2010. 78(6): p. 1510-22. 


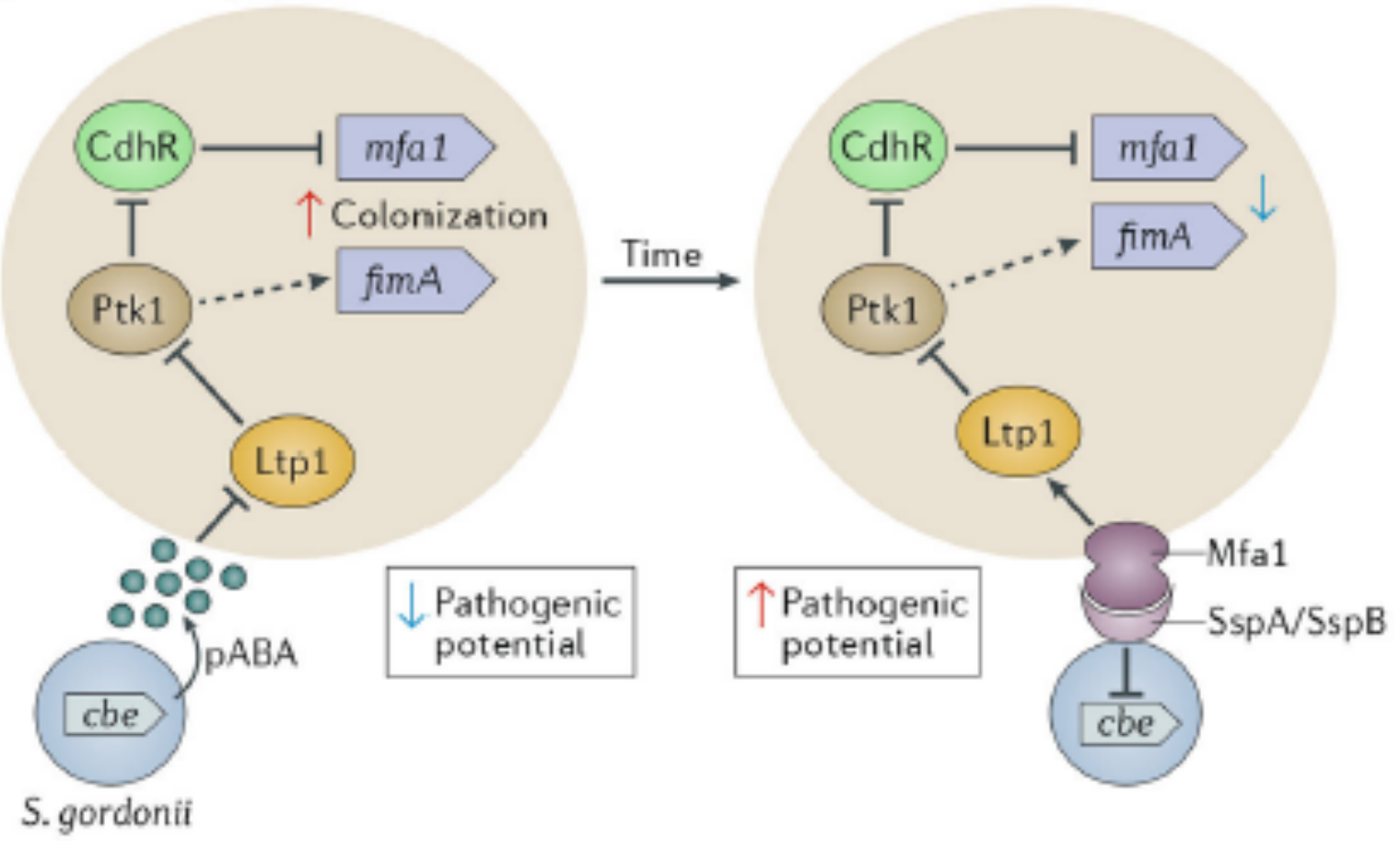

Figure 6b: Schematic representation of $P$. gingivalis - S. gordonii signalling mechanism. (b) Binding of Mfa1 $-\mathrm{SspB}$ increases Ltp1 activity and reduces the expression of fimbrial adhesins. Mfa1-SspB binding also decreases the expression of chorismate binding enzyme (Cbe), resulting in reduced pABA production. Increased Ltp1 activity and reduced Cbe expression limits bacterial aggregation and enhances the pathogenicity of $P$. gingivalis.

Image from: Lamont, R.J., H. Koo, and G. Hajishengallis, The oral microbiota: dynamic communities and host interactions. Nat Rev Microbiol, 2018. 16(12): p. 745-759. 


\section{Our approach}

In our previous work, we demonstrated that a synthetic peptide, consisting of residues 1167 to 1193 of the surface protein SspB expressed by S. gordonii, designated BAR (SspB Adherence Region), blocks the Mfa1-SspB interaction and reduces the virulence of $P$. gingivalis in murine models of periodontitis $[67,129]$. However, free peptide is only retained transiently in the oral cavity owing to the constant flow of saliva. Moreover, while BAR potently inhibited the initial adherence of $P$. gingivalis to $S$. gordonii, it was less effective at inhibiting pre-established $P$. gingivalis biofilms.

To enhance the efficacy of BAR peptide $\left(\mathrm{IC}_{50}=1.3 \mu \mathrm{M}\right)$, we developed polymeric poly (lacticco-glycolic acid) (PLGA) nanoparticles (NPs) encapsulating BAR (BAR-NPs). These NPs inhibited $P$. gingivalis $-S$. gordonii biofilm formation more potently relative to free peptide $\left(\mathrm{IC}_{50}\right.$ $=0.7 \mu \mathrm{M})$. BAR-NPs also disrupted pre-established biofilms more potently than free BAR.

We envision our NPs to be ultimately incorporated in oral hygiene products such as oral gels which are used two to three times daily. Hence, we ideally seek to develop NPs that will be retained in the oral cavity and release inhibitory concentrations of BAR peptide for a minimum of 8 to 12 hours. However, BAR-NPs released $>50 \%$ of BAR peptide within the first $2 \mathrm{hr}$ of delivery and would exhibit low retention in an open flow environment such as the oral cavity [133]. Hence, the BAR-NPs would benefit from a strategy that would improve their retention in the oral cavity and promote a gradual release of the BAR peptide.

Several approaches have been employed to improve NP retention, including alteration of properties such as surface charge and hydrophobicity, and functionalizing NPs with nonspecific mucoadhesive or specific targeting ligands that bind to host receptors [134]. As 
previously discussed, the use of specific targeting ligands has been shown to increase NP binding efficiency at target sites, due to multivalent interactions with host cell receptors [107109]. These ligands seek to minimize non-specific interactions between NPs and non-target cells reducing indiscriminate distribution of active agents at non-target sites and promoting localized delivery at target sites, thereby enhancing NP efficacy $[110,111]$. Thus, developing actively targeted NPs, using specific ligands, is a promising strategy to enhance the efficacy of NPs. For our experiments, we utilized Coaggregation Factor A protein (CafA) as a targeting ligand to functionalize the BAR-NPs.

\section{Coaggregation Factor A Protein (CafA)}

Actinomyces oris expresses two types of heterodimeric fimbriae:

Type 1 - Mediates the binding of the bacteria to the proline rich salivary proteins which coat the tooth surface.

Type 2 - Mediates the coaggregation of streptococci and actinomyces species [135].

The type 2 fimbriae is composed of a fimbrial shaft made of FimA subunits and tip fimbrillin consisting of either FimB or CafA protein. During plaque formation, CafA protein binds to the GalNAcß1-3Gal motif of the receptor polysaccharides (RPS) found on oral commensal streptococci such as S. gordonii and S. oralis, facilitating the coaggregation of actinomyces and streptococci. Since CafA is the key adhesin which mediates actinomyces-streptococci binding [136], we anticipated that functionalization of NPs with CafA would enable us to actively target NPs to areas of the oral cavity harboring commensal streptococci, to gradually release BAR in $P$. gingivalis preferred niches.

We hypothesized that modifying the surface of BAR-encapsulated NPs with CafA, would enhance NP efficacy by augmenting their adhesion to commensal streptococci, facilitating retention for a longer duration, promoting more gradual release of BAR peptide, and resulting in potent inhibition of $P$. gingivalis adhesion to $S$. gordonii in a dual-species biobiofilm. 


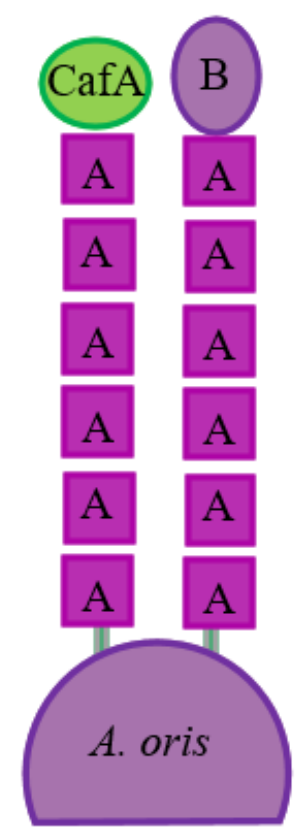

Figure 7: Schematic representation of type 2 fimbriae of $A$. oris. The type 2 fimbriae facilitates bacterial coaggregation and consists of a shaft comprising of FimA subunit and tip fimbrillin consisting of either CafA or FimB.

Image adapted from: Reardon-Robinson, M.E., et al., Pilus hijacking by a bacterial coaggregation factor critical for oral biofilm development. PNAS, 2014. 111(10): p. 3835-40. 


\section{CHAPTER 2}

\section{HYPOTHESIS AND SPECIFIC AIMS}

Antibiotics are commonly used as adjuncts in the treatment of periodontal diseases to prevent its reoccurrence [42-44]. However, the effectiveness of antibiotics in the treatment of periodontal diseases is limited owing to (i) biofilm-mediated resistance and (ii) reduced susceptibility of resistant pathogens in subgingival microflora [58]. Therefore, there is a compelling need to develop novel, targeted, treatment strategies beyond antibiotics for the prevention and treatment of periodontal diseases.

This project builds on previous work which demonstrated that a synthetic peptide (BAR) blocks the $P$. gingivalis $-S$. gordonii interaction and reduces the virulence of $P$.gingivalis in the murine model of periodontitis. Furthermore, nanoparticles encapsulating BAR peptide inhibit the biofilm formation more potently relative to free BAR [133]. However, similar to free peptide, NP delivery vehicles may exhibit low retention in an open flow environment such as the oral cavity, necessitating administration of higher, more frequent doses. Furthermore, due to the time frame of peptide release (over the course of hours) from BAR-NPs, we hypothesized that BAR-NPs may benefit from a strategy that augments their retention in an open flow environment. Our vision is to develop delivery vehicles that will ultimately be incorporated into oral healthcare products such as oral gels which are commonly used twice daily. Therefore, ideally, we seek to formulate nanoparticles that will be retained in the oral cavity and release inhibitory concentrations of BAR peptide for a minimum of 8 to 12 hours. 
Our hypothesis is that modifying the surfaces of NPs with specific targeting moieties such as CafA will (i) augment the retention of the NPs in the oral cavity via multivalent interactions and increased avidity of contact with targeted receptor polysaccharides and (ii) prolong the release of BAR peptide from the NPs by facilitating a more gradual release of the encapsulant.

Thus, the efficacy of the BAR- NPs can be further enhanced by modifying the surfaces of the BAR-NPs with a specific targeting moiety, such as CafA. Surface modification would augment the adhesion of the NPs to specific receptors on bacterial surfaces, facilitate their accumulation at target sites and promote a gradual, localized release of the BAR peptide in P. gingivalis preferred niches.

To accomplish this, we propose three specific aims:

Specific Aims

1. Synthesize and characterize CafA-modified nanoparticles encapsulating BAR peptide.

2. Evaluate the functionality of the surface modification and the release kinetics of BAR peptide from surface-modified NPs.

3. Determine the efficacy of the CafA-modified NPs using biofilm inhibition assays. 
(A)
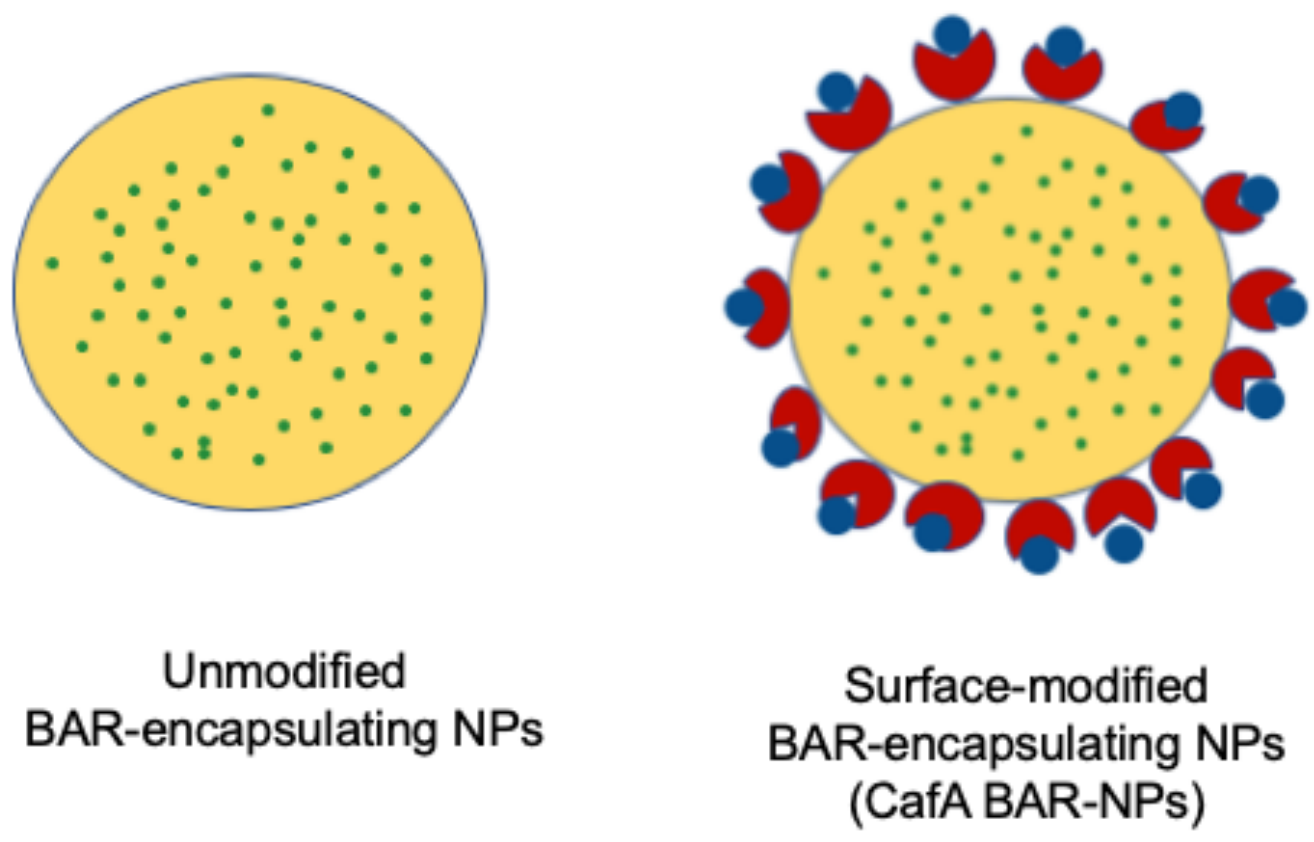

(B)
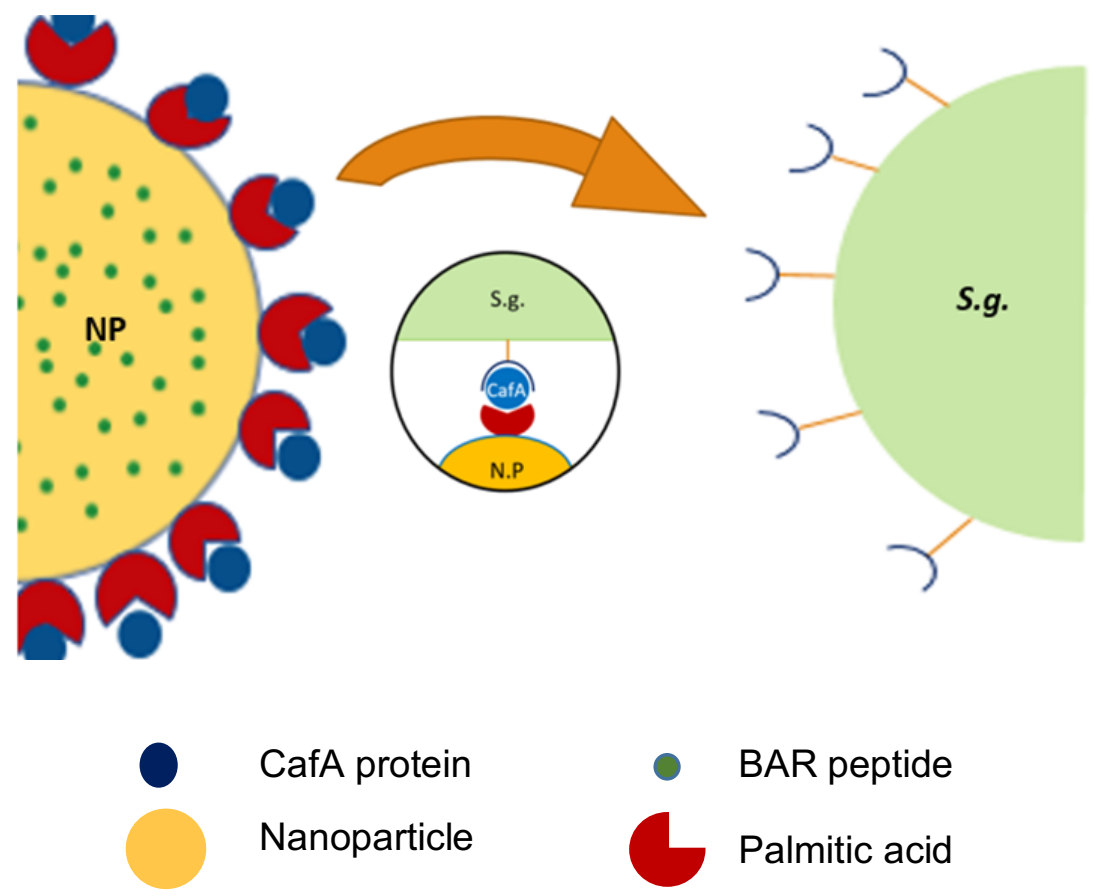

Figure 8: (A) Schematic representation of nanoparticles and (B) NP targeting strategy. Surface modification of nanoparticles with CafA protein will aid in directing NPs to $S$. gordonii for targeted delivery of BAR peptide. 
CHAPTER 3

MATERIAL AND METHODS

\section{Peptide Synthesis}

BAR peptide consists of residues 1167 to 1193 of the SspB surface protein expressed by S. gordonii. BAR peptide constitutes the following amino acid sequence:

\section{$\mathrm{NH}_{2}$-LEAAPKKKVQDLLKKANITVKGAFQLFS-COOH}

To visualize and quantify the release of the peptide from CafA-modified NPs, 6-carboxyfluorescien was covalently attached to the $\varepsilon$ - amine of the lysine residue highlighted in red in the peptide sequence above to produce fluorescent BAR (F-BAR). Functional studies of CafA-modified NPs was carried out using NPs encapsulating unlabeled BAR peptide. Both labelled and unlabeled BAR peptide were synthesized by Biosynthesis, Inc. (Lewisville, TX) and were obtained with a greater than $94 \%$ purity.

\section{Growth of Bacterial Strains}

Porphyromonas gingivalis ATCC 33277 was cultured in Trypticase soy broth media (TSBY media) (Difco laboratories Inc., Livonia, MI, USA) supplemented with $0.5 \%(\mathrm{w} / \mathrm{v})$ yeast extract, $1 \mu \mathrm{g} / \mathrm{ml}$ menadione, and $5 \mu \mathrm{g} / \mathrm{ml}$ hemin. The growth medium was reduced for $24 \mathrm{hr}$ in an anaerobic chamber $(10 \% \mathrm{CO} 2,10 \% \mathrm{H} 2$ and $80 \% \mathrm{~N} 2)$. Twenty mls of reduced media was subsequently inoculated with $2 \mathrm{mls}$ of an overnight $P$. gingivalis culture and incubated under anaerobic conditions for $48 \mathrm{hrs}$ at $37^{\circ} \mathrm{C}$. S. gordonii DL-1, S.oralis SO34, S.mutans KPSP2 and $A$ actinomycetemcomitans 652 were cultured aerobically without shaking in brain-heart infusion $(\mathrm{BHI})$ broth supplemented with $1 \%$ yeast extract for $16 \mathrm{hr}$ at $37^{\circ} \mathrm{C}$. 


\section{CafA expression and purification}

CafA synthesis was done by isolating the genomic DNA of Actinomyces oris (ATCC 43146) from $10 \mathrm{~mL}$ of an overnight culture using the Wizard Genomic DNA purification kit (Promega, Madison $\mathrm{WI}$ ) as specified by manufacturer. The cafA gene was amplified by PCR using 200 ng of genomic DNA as the template and 30 pmol each of the following primers: Forward: 5'AAG GAT CCC TGA GGC CGT TCA -3'; Reverse: 5'- CCG GAA TTC TAC GAC TTG CGG TTG GAG-3'. PCR amplification was conducted by denaturation at $94^{\circ} \mathrm{C}$ for 2 min, annealing of primers and template at $63^{\circ} \mathrm{C}$ for $30 \mathrm{~s}$, strand extension at $72^{\circ} \mathrm{C}$ for $2 \min 45 \mathrm{~s}$ for 30 cycles, followed by a final extension cycle at $72^{\circ} \mathrm{C}$ for $5 \mathrm{~min}$.

The PCR product was subsequently electrophoresed in $1 \%$ agarose at $90 \mathrm{~V}$ for $40 \mathrm{~min}$ and the cafA band was excised and purified using the gel purification kit (Qiagen). The purified cafA DNA $(1 \mu \mathrm{g})$ and a sample of the pGEX-6p-1 expression vector $(0.5 \mu \mathrm{g})$ were digested with $\mathrm{BamHI}$ and $\mathrm{EcoRI}$ overnight at $37^{\circ} \mathrm{C}$. Prior to ligation, $50 \mu \mathrm{L}$ of the digested vector were dephosphorylated with $4 \mu \mathrm{L}$ calf intestinal alkaline phosphatase (NEB) at $37^{\circ} \mathrm{C}$ for $30 \mathrm{~min}$. Subsequently, $3 \mu \mathrm{L}$ of protease $\mathrm{K}$ were added and incubated for $30 \mathrm{~min}$ at $50^{\circ} \mathrm{C}$ to terminate the reaction. The vector and cafA fragments were purified using the DNA clean and concentrator kit (Zymoresearch) and ligated with T4 ligase. Ligation reactions comprised $3 \mu \mathrm{L}$ vector, $5 \mu \mathrm{L}$ cafA fragment, $1 \mu \mathrm{L} 10 \mathrm{x}$ ligase buffer and $1 \mu \mathrm{L}$ T4 ligase.

The ligation mixture was initially transformed into $E$. coli Top10. Fifty $\mu \mathrm{L}$ of competent $E$. coli Top10 were incubated with $5 \mu \mathrm{L}$ of ligation mixture on ice for $30 \mathrm{~min}$, then the sample was heat shocked at $42^{\circ} \mathrm{C}$ for $45 \mathrm{~s}$ and placed on ice for $2 \mathrm{~min}$. Two hundred $\mu \mathrm{L}$ of SOC media were added, the sample was incubated at $37^{\circ} \mathrm{C}$ for $1 \mathrm{hr}$ and plated on LB agar. After overnight incubation at $37^{\circ} \mathrm{C}$, single colonies were selected and cultured in $5 \mathrm{~mL}$ LB broth supplemented with $100 \mu \mathrm{g}$ ampicillin. Plasmid purification was carried out using the miniprep kit (Qiagen) and the cafA insert was excised and confirmed by sequencing. 
For CafA expression, the purified cafA plasmid was transformed into E. coli BL21 using the transformation protocol described above. After selecting and confirming the appropriate transformant, $400 \mathrm{~mL}$ of LB broth was inoculated with $10 \mathrm{~mL}$ of an overnight culture and incubated to $\mathrm{OD}_{600}$ of 0.5 . Protein expression was induced by the addition of $0.5 \mathrm{mM}$ IPTG and the culture was then incubated at $18^{\circ} \mathrm{C}$ for $17 \mathrm{hr}$. After centrifugation at $4,250 \times \mathrm{g}$, the cell pellet was suspended in $40 \mathrm{~mL} 50 \mathrm{mM}$ Tris, $100 \mathrm{mM} \mathrm{NaCl}, 1 \mathrm{mg} / \mathrm{mL}$ lysozome, $10 \mu \mathrm{g} / \mathrm{mL}$ Dnase I, protease inhibitor cocktail, $10 \mathrm{mM} \mathrm{CHAPS}$, incubated overnight at $4^{\circ} \mathrm{C}$, then for an additional $2 \mathrm{hr}$ at $25^{\circ} \mathrm{C}$. The cell suspension was then sonicated for 2 min on ice.

CafA purification was carried out with the Pierce GST Spin Purification Kit (Thermo Fisher). Seventeen $\mathrm{mL}$ of crude cell lysate were bound to the GST column for $2 \mathrm{hr}$ at room temperature and the column was then centrifuged to remove unbound protein according to the specifications of the manufacturer. After washing the column with loading buffer, the GST tag was cleaved by the addition of $50 \mu \mathrm{L}$ precision protease (GE Health) and overnight incubation at $4^{\circ} \mathrm{C}$. Released CafA was then collected by centrifugation. The sample was then sequentially dialyzed against $30 \mathrm{mM}, 20 \mathrm{mM}$, and $10 \mathrm{mM}$ Tris for $2 \mathrm{hr}$ each. CafA purity was determined by PAGE gels and protein concentration was determined using the BCA assay (Pierce).

\section{Conjugation of CafA protein with Palmitic acid (CafA-Palmitate Synthesis)}

CafA-palmitate was synthesized as previously described [137-139]. Briefly, $2 \mathrm{mg}$ of purified CafA was dissolved in $1.2 \mathrm{~mL}$ of $2 \%(\mathrm{w} / \mathrm{v})$ sodium deoxycholate (NaDC) in phosphate-buffered saline (137 mM NaCl, $2.7 \mathrm{mM} \mathrm{KCl}, 1.8 \mathrm{mM} \mathrm{KH}_{2} \mathrm{PO}_{4}, 10 \mathrm{mM} \mathrm{Na}_{2} \mathrm{HPO}_{4}$; PBS) and warmed to $37^{\circ} \mathrm{C}$. Next, a solution with 14 -fold molar excess of the palmitic acid-N-hydroxysuccinimide ester (NHS- palmitic acid; Sigma-Aldrich, St Louis, MO, USA) was prepared by dissolving NHS-palmitic acid in $2 \%(\mathrm{w} / \mathrm{v}) \mathrm{NaDC}$ at $0.125 \mathrm{mg} / \mathrm{mL}$. The solution was sonicated until well mixed in an ultrasonic bath and $800 \mathrm{uL}$ of this solution was added dropwise to the reaction 
vial containing CafA and reacted overnight at $37^{\circ} \mathrm{C}$. To remove excess fatty acid and hydrolyzed ester, reactants were dialyzed against $1.2 \mathrm{~L}$ of PBS with $0.15 \%$ deoxycholate, using a 3,500 molecular weight cut-off dialysis tube. After overnight dialysis at $37^{\circ} \mathrm{C}$, CafApalmitate was stored at $4^{\circ} \mathrm{C}$ until use.

\section{Synthesis of CafA-modified nanoparticles}

Nanoparticles were synthesized using poly(lactic-co-glycolic acid) (PLGA) carboxylterminated polymer $(0.55-0.75 \mathrm{dL} / \mathrm{g}$ inherent viscosity; LACTEL $®)$. To formulate CafAmodified nanoparticles, a previously described oil-in-water (o/w) single emulsion technique was used [140, 141]. Briefly, 100 mg PLGA was dissolved in $2 \mathrm{~mL}$ dichloromethane (DCM) by overnight incubation at $25^{\circ} \mathrm{C}$. The next day, $2 \mathrm{~mL}$ of $5 \%(\mathrm{w} / \mathrm{v})$ polyvinyl alcohol (PVA) was added to $2 \mathrm{~mL}$ CafA-palmitate solution. This solution was vortexed and $2 \mathrm{~mL}$ of PLGA/DCM solution was added to it in a dropwise manner. The resulting solution was ultrasonicated and excess DCM was evaporated by adding the solution to $50 \mathrm{~mL}$ of $0.3 \%(\mathrm{w} / \mathrm{v})$ PVA and mixing using a magnetic stir bar for $3 \mathrm{hr}$. After evaporation, the NP solution was centrifuged at 13,000 rpm $(20,442 \times \mathrm{g})$ at $4^{\circ} \mathrm{C}$ for $10 \mathrm{~min}$. The supernatant was discarded, and the NPs were washed twice with deionized water ( $\mathrm{diH} 2 \mathrm{O})$ followed by centrifugation at $13,000 \mathrm{rpm}(20,442 \times \mathrm{g})$ at $4^{\circ} \mathrm{C}$ for $10 \mathrm{~min}$. After washing, CafA-modified NPs were suspended in $5 \mathrm{~mL}$ of diH2O, freeze dried at $-80^{\circ} \mathrm{C}$ and lyophilized.

\section{Synthesis of CafA-modified NPs encapsulating C6/F-BAR/BAR}

For our experiments, three different types of CafA-modified NPs were synthesized. CafAmodified NPs encapsulating the fluorescent dye, Coumarin6 (C6), were synthesized to assess the binding functionality of CafA surface modification. CafA-modified NPs encapsulating fluorescent BAR (F-BAR) were synthesized to determine the loading and controlled release 
characteristics of the NPs, and CafA-modified NPs encapsulating unlabeled BAR were synthesized to determine the efficacy of NP-mediated inhibition of $P$. gingivalis adherence to streptococci using a two-species biofilm model.

CafA-modified NPs encapsulating C6 were synthesized using a previously described w/o/w double emulsion solvent evaporation technique [138, 139]. Briefly, C6 was dissolved overnight in $200 \mu \mathrm{l}$ DCM at a concentration of $15 \mu \mathrm{g} / \mathrm{mg}$ PLGA. In parallel, $100 \mathrm{mg}$ of PLGA crystals were dissolved in $2 \mathrm{ml}$ of $\mathrm{DCM}$ by overnight incubation at $25^{\circ} \mathrm{C}$. The following day, the $\mathrm{C} 6$ DCM solution was first emulsified in the PLGA/DCM solution by vortexing followed by ultrasonication to achieve a homogenous suspension. Next, the homogenous suspension was added dropwise to a mixture of $2 \mathrm{ml}$ of $5 \%(\mathrm{w} / \mathrm{v})$ polyvinyl alcohol (PVA) and $2 \mathrm{ml}$ CafApalmitate while vortexing followed by ultrasonication. Excess DCM was evaporated and NPs were collected as described above. CafA-modified NPs encapsulating F-BAR/BAR were synthesized using a similar approach. All synthetic reactions were protected from exposure to light. For the synthesis of CafA-modified NPs encapsulating either F-BAR or unlabeled BAR, the peptide was dissolved in $200 \mu \mathrm{l}$ Tris EDTA buffer (VWR; $100 \mathrm{mM}$ Tris $\mathrm{HCl}, 10$ mM EDTA at a pH of 8.0; T.E buffer) at a concentration of $43 \mu \mathrm{g} / \mathrm{mg}$ PLGA [133]. 


\section{(A)}

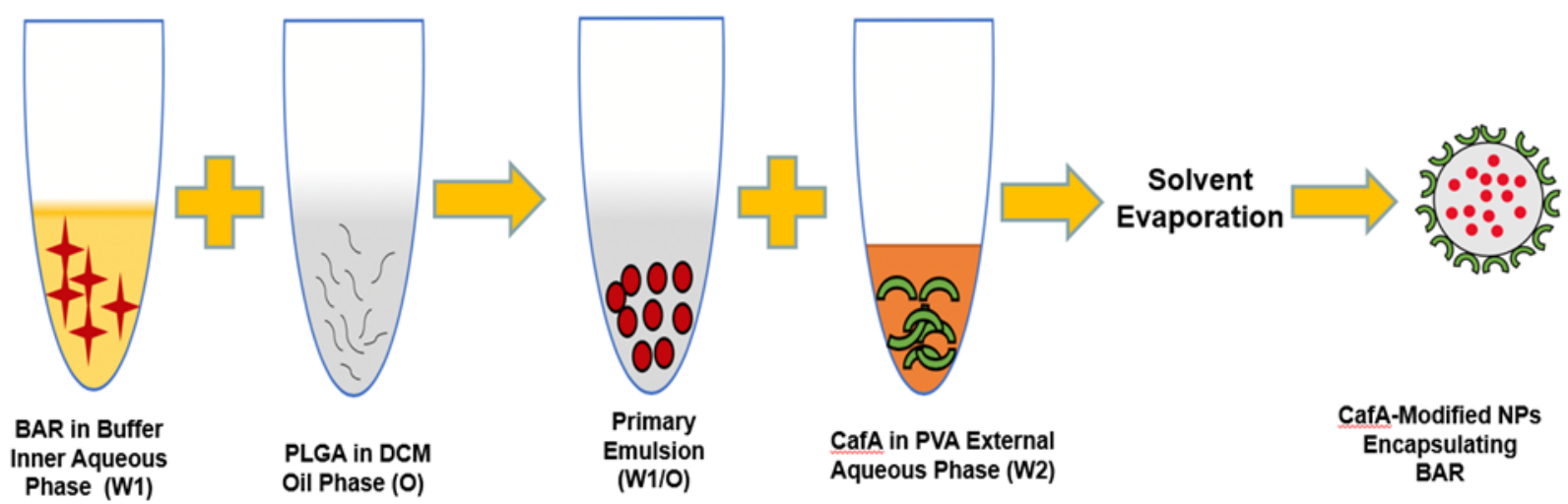

(B)

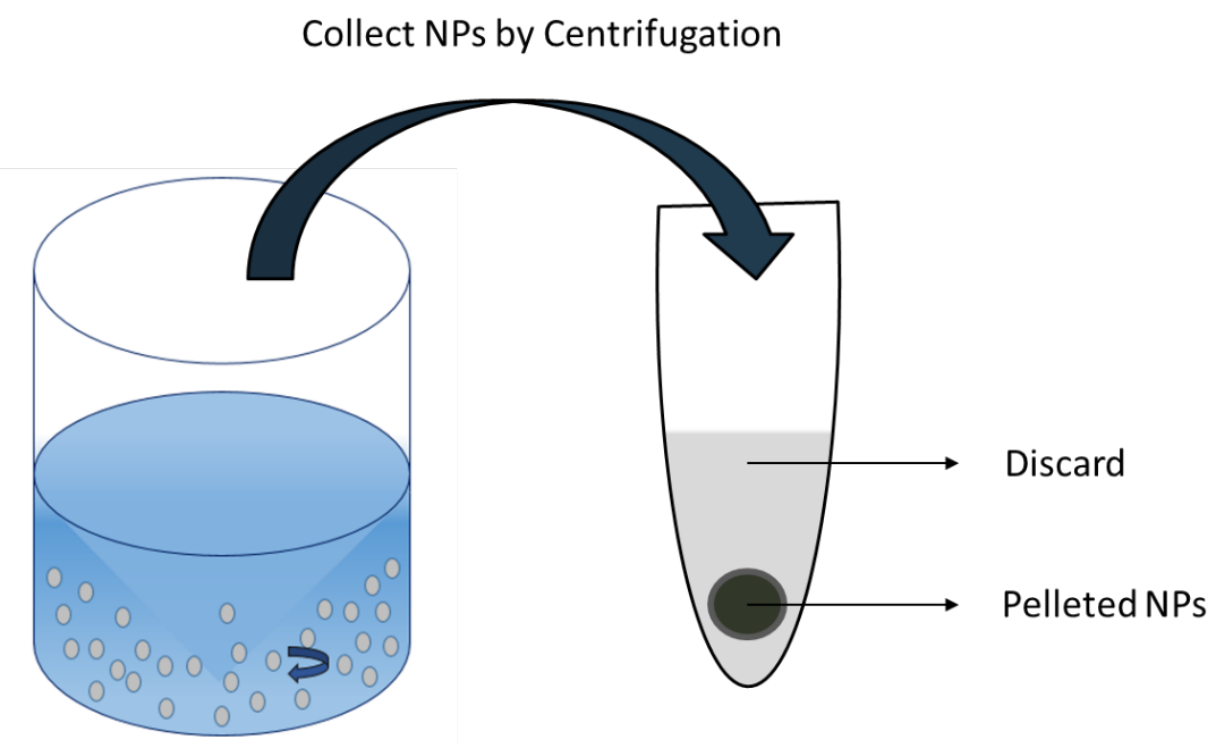

Figure 9: (A) Schematic representation of synthesis of CafA-modified NPs encapsulating BAR peptide using double emulsion solvent evaporation technique. (B) Collection of NPs after solvent evaporation, centrifugation and washing.

Bottom image adapted from McCall, R.L., Sirianni, R.W. PLGA Nanoparticles Formed by Single or Double-emulsion with Vitamin E-TPGS. J. Vis. Exp. (82), e51015. 


\section{NP Characterization: NP morphology and size}

Unhydrated NP morphology, diameter, and size distribution were determined using scanning electron microscopy (SEM, XL-30 ESEM-FEG SEM, FEI Company, USA). Lyophilized NPs were mounted on carbon tape and sputter coated with a thin layer of gold/palladium. Average diameters of 500 particles were determined from SEM images $(n=3)$ using image analysis software (ImageJ, National Institutes of Health, version 1.5a, ImageJ.nih.gov).

\section{Quantification of Surface Density of CafA}

CafA-modified NPs were synthesized using varying input concentrations of CafA protein (5 to $80 \mathrm{ug} / \mathrm{mg}$ polymer). For each input condition, the resulting concentration of CafA conjugated to the NP surface was measured using the microBCA assay (Pierce). CafAmodified NPs (1 mg) were suspended in 1\% dimethyl sulfoxide (DMSO) in PBS. Aliquots (100 $\mathrm{uL}$ ) of the NP samples were analyzed in triplicate in a microtiter plate and NP-associated absorbance was measured by spectrophotometry at a wavelength of $562 \mathrm{~nm}$. The concentration of CafA was determined by comparing absorbance values to a known standard curve of CafA and subtracting the background absorbance values of unmodified NPs (control group).

\section{Loading and release kinetics of BAR peptide from unmodified and CafA-modified NPs} Nanoparticles modified with an intermediate density of CafA (20 ug/mg polymer) were selected for subsequent characterization and functionality studies. To determine BAR peptide loading, approximately 2 mg CafA-modified NPs encapsulating F-BAR were dissolved in $1 \mathrm{~mL}$ DMSO. Aliquots $(100 \mathrm{uL})$ of the NP samples were analyzed in triplicate in a microtiter plate and the amount of F-BAR in the dissolved solution was determined by measuring fluorescence 
(488/518 $\mathrm{nm}$ excitation/emission) and quantified by comparing these values to a known standard curve of F-BAR.

To analyze the release kinetics of F-BAR, aliquots of CafA-modified and unmodified NPs encapsulating F-BAR were incubated in microcentrifuge tubes containing $1 \mathrm{~mL}$ PBS $(\mathrm{pH} 7.4)$ at $37^{\circ} \mathrm{C}$ with gentle horizontal agitation. At fixed time points $(1,2,4,8$, and $24 \mathrm{hr})$ after the initial suspension, the samples were centrifuged at $18,900 \times \mathrm{g}$ and the supernatant was collected. The pelleted NPs were then suspended in fresh PBS and incubated until the next time point. The amount of F-BAR in the supernatant was determined by measuring fluorescence (488/518nm excitation/emission) and quantified by comparing these values to a known standard curve of F-BAR.

\section{Determination of functionality of surface modification}

The functionality of surface modification and preservation of the function of CafA protein during NP synthesis was analyzed using two approaches.

To determine the duration of retention of CafA-modified C6 NPs on S. gordonii DL-1 cells, S. gordonii was cultured as previously described and bacterial cells were harvested by centrifuging $10 \mathrm{~mL}$ of culture at $3700 \times \mathrm{g}$ for $5 \mathrm{~min}$. The supernatant was discarded and the pelleted cells were suspended in $1 \mathrm{~mL}$ of 1 X PBS. The O.D. at $600 \mathrm{~nm}$ of the cell suspension was adjusted to 0.2 and $100 \mu \mathrm{L}$ of the $S$. gordonii cell suspension was added to each well of a 96 -well microtiter plate and incubated overnight at $4^{\circ} \mathrm{C}$. After removing unbound cells, the wells were blocked for non-specific binding with $300 \mu \mathrm{L}$ of $0.3 \%$ bovine serum albumin (BSA) for $1 \mathrm{hr}$. Thereafter, the microtiter plate was washed three times with 1 X PBS containing $0.05 \%$ Tween (PBST). Immobilized S. gordonii cells were then incubated with $100 \mu \mathrm{L}$ of CafAmodified C6 NPs $(0.25 \mathrm{mg} / \mathrm{mL})$, avidin-modified C6 NPs $(0.25 \mathrm{mg} / \mathrm{mL})$ or PBST in the absence of NPs in triplicate for $1 \mathrm{hr}$ on a rocker platform. After washing three times with PBST, the cell- 
associated fluorescence was measured using Synergy HT reader (BioTek, Winooski, VT, USA) (485/520 nm excitation/emission). After subtracting the control fluorescence (S. gordonii in PBST), this initial reading (at $t=$ zero) was defined as $100 \%$ binding. After obtaining the initial reading, $100 \mu \mathrm{L}$ of PBST was added to each well and at fixed time points $(1,2,4$ and 8 $\mathrm{hr}$ ), the PBST was removed and the cell-associated fluorescence that remained was measured. Subsequently, an additional aliquot of fresh PBST was added per well and incubated until the next time point was reached.

For determining the specificity of CafA adhesion, the adherence of CafA-modified C6 NPs to S. gordonii DL-1, S. oralis SO34, P. gingivalis ATCC 33277, A. actinomycetemcomitans 652 or S. mutans KPSP2 cells was measured. CafA binds to receptor polysaccharides (RPS) found only on commensal oral streptococci such as S. gordonii and S. oralis. It does not bind to bacteria that are RPS- negative and therefore, $P$. gingivalis ATCC 33277, A. actinomycetemcomitans 652 and S. mutans KPSP2 were selected as negative bacterial controls. Each of the organisms was cultured and harvested as described previously, and the final O.D. at $600 \mathrm{~nm}$ for each cell suspension was adjusted to 0.2 . The bacterial cells were immobilized on a 96-well microtiter plate as described above and after overnight incubation, wells were blocked for non-specific binding with $300 \mu \mathrm{L}$ of $3 \%$ bovine serum albumin (BSA) for $1 \mathrm{hr}$. The plate was washed three times with PBST and immobilized bacterial cells were incubated with $100 \mu \mathrm{L}$ of CafA-modified C6 NPs $(0.25 \mathrm{mg} / \mathrm{mL})$ or with PBST in triplicate for 1 $\mathrm{hr}$ on a rocker platform. The microtiter plate was again washed three times with PBST and cell-associated fluorescence was measured (485/520 nm excitation/emission). To determine the final cell associated fluorescence, the reading obtained from bacteria incubated in PBST alone (background) was subtracted from that of bacteria incubated with CafA-modified C6 NPs. Data was analyzed using an unpaired t-test. 


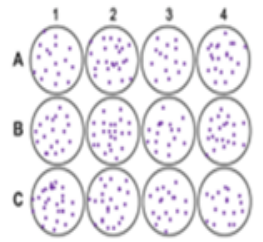

Immobilize S. g. on a microtiter plate
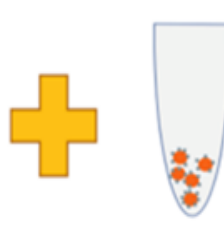

CafA C6-NPs

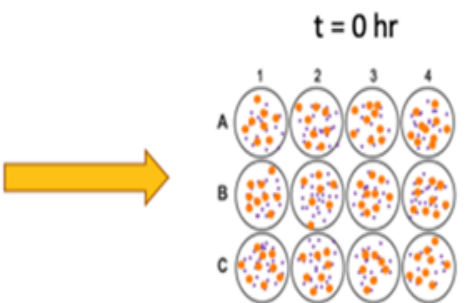

After removal of unbound NPs, measure bacteriaassociated fluorescence at each time-points

Figure 10: Schematic of duration of retention assay. S. gordonii cells were immobilized on a microtiter plate and incubated with CafA C6-NPs. At fixed time points, the supernatant containing the unbound NPs was removed and the cell associated fluorescence was measured. Thereafter, fresh buffer was added to the wells, until the next time point was reached. Avidin-modified C6 NPs were used as controls. To measure specificity of adhesion, adherence of CafA-modified NPs to S. mutans KPSP2, S. oralis SO34, P. gingivalis ATCC 33277 or A. actinomycetemcomitans 652 cells was compared to the level of adherence to $S$. gordonii DL-1 cells. 


\section{CafA-modified NP-mediated inhibition of $\boldsymbol{P}$. gingivalis adherence to streptococci}

S. gordonii DL-1 was cultured as previously described and bacterial cells were harvested by centrifuging $10 \mathrm{~mL}$ of culture at $3700 \times \mathrm{g}$ for $5 \mathrm{~min}$. The supernatant was discarded, and the pelleted cells were suspended in $1 \mathrm{~mL}$ of $1 \mathrm{X}$ PBS in a microcentrifuge tube. The cells were labelled with $20 \mu \mathrm{L}$ of $10 \mathrm{mM}$ hexidium iodide (Thermo Fisher Scientific) for $15 \mathrm{~min}$ on a rocker platform at room temperature. The microcentrifuge tube was covered with foil, centrifuged at $3700 \times \mathrm{g}$ for $5 \mathrm{~min}$, and the pelleted cells were suspended in $1 \mathrm{~mL}$ of 1 X PBS. The O.D. at $600 \mathrm{~nm}$ was measured as previously described and adjusted to 0.8 . One $\mathrm{mL}$ of the resulting cell suspension was added to each well of a 12-well microtiter plate containing a glass coverslip. The cells were incubated overnight under anaerobic conditions on a rocker platform and protected from light.

On the following day, the wells were washed to remove unbound $S$. gordonii cells. The immobilized S. gordonii cells were incubated with CafA-modified BAR NPs (treatment) or CafA-modified blank NPs (control) at a concentration of $240 \mu \mathrm{g} / \mathrm{mL}$ for different durations on a rocker platform. Due to the $50 \%$ inhibitory concentration $\left(\mathrm{IC}_{50}\right)$ of free BAR peptide equivalent to $1.3 \mu \mathrm{M}$ or $\sim 4 \mu \mathrm{g}$, and NP loading results, we calculated that $240 \mu \mathrm{g}$ CafAmodified BAR NPs would encapsulate an equivalent amount of BAR. After the first hour of binding $(t=0)$ and at each subsequent time point $(t=2,4,8,12 \mathrm{hr})$ the supernatant containing the unbound NPs and released BAR was removed and $P$. gingivalis was added in triplicate to the control and treatment plates as described below.

P. gingivalis ATCC 33277 was cultured and harvested as previously described. $P$. gingivalis was labelled with $15 \mu \mathrm{L}$ of $5-(6)$ carboxyfluorescien-succinylester $(4 \mathrm{mg} / \mathrm{mL}$ ) for $30 \mathrm{~min}$, centrifuged at $3700 \times \mathrm{g}$ for 2 min and the pelleted cells were suspended in $1 \mathrm{~mL}$ of $1 \mathrm{X}$ PBS. The O.D. at $600 \mathrm{~nm}$ was measured and adjusted to 0.4 . At each time point, $1 \mathrm{~mL}$ of labelled P. gingivalis cell suspension (O.D. 0.4) was added to the treatment and control plates in 
triplicate. The plates were incubated at $37{ }^{\circ} \mathrm{C}$ for $24 \mathrm{hr}$ under anaerobic conditions. The subsequent day the supernatant was removed, the wells were washed with 1 X PBS to remove the unbound bacterial cells. The adherent cells were fixed with $4 \%(w / v)$ paraformaldehyde. The coverslips were mounted on a glass slide using Prolong gold anti-fade reagent and fixed with clear nail polish. The prepared slides were stored at $4^{\circ} \mathrm{C}$.

\section{Confocal Microscopy and Imaging}

The dual-species biofilms were visualized using a LEICA SP8 confocal microscope (Lieca Microsystems Inc., Buffalo Grove, IL) under 60 X magnification. Three dimensional z-stack biofilm images were obtained using a z-step size of $0.7 \mu \mathrm{m}$. Images were analyzed using Volocity software (version 6.3; Perkin Elmer, Waltham, MA, USA) to quantify the bacterial populations by quantifying fluorescence ( $S$. gordonii - red, $P$. gingivalis - green). Adherence of $P$. gingivalis to streptococci was determined by measuring the green to red fluorescence ratio (GR). Inhibition at each time point was analyzed in triplicate (treatment and control plates) and three independent frames were obtained for each well. The percentage of $P$. gingivalis inhibition was calculated using the formula: (1- GR treatment /GR control) * 100. The mean and S.D. of inhibition at each time point was calculated and the data was analyzed using a paired t-test. 


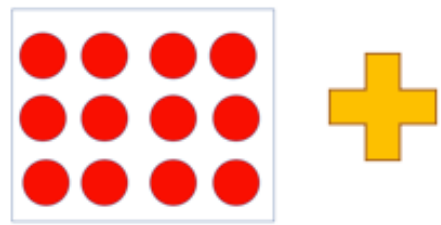

Immobilized S. $g$. labelled with hexidium iodide (red, R)

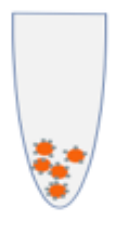

CafA BAR-NPs

\section{Incubate}

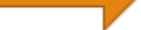

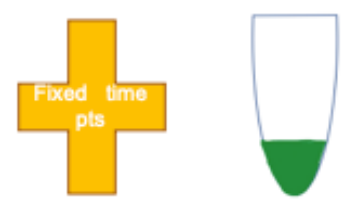

P. g. labelled with carboxyfluorescein succinimidyl ester (green, G)
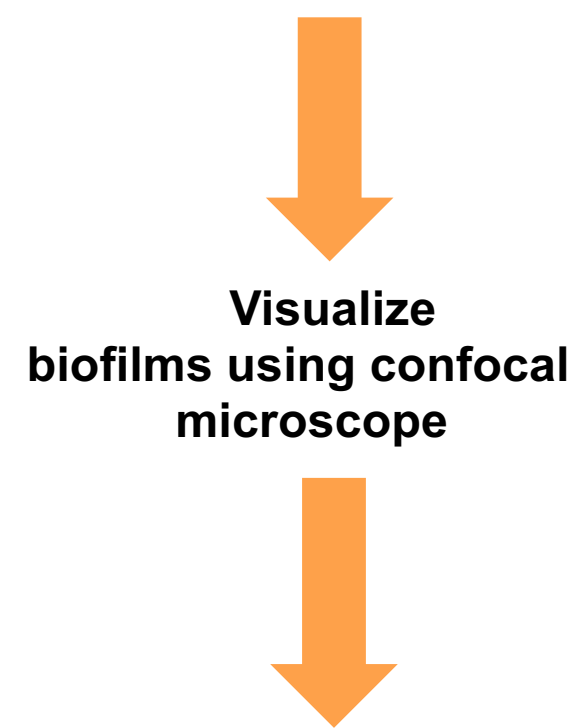

\section{Measure GR ratio using Volocity software $\%$ adherence inhibition $P . g .=1-G R(S) / G R(C) \times 100$}

Figure 11: Schematic representation of inhibition assay using dual-species biofilm. The efficacy of the CafA-modified NPs was evaluated by performing functional inhibition assays using a two species biofilm model. 


\section{CHAPTER 4}

\section{RESULTS}

\section{NP Characterization: NP morphology and size}

The morphology of CafA-modified BAR NPs, relative to unmodified BAR NPs, is shown in

Figure 12. CafA-modified BAR NPs demonstrated a spherical morphology and were smaller relative to unmodified BAR NPs. The average unhydrated diameters of CafA-modified BAR NPs and unmodified BAR NPs measured from SEM images were $89.7 \pm 26.3 \mathrm{~nm}$ and 165.8 $\pm 33.4 \mathrm{~nm}$, respectively. 

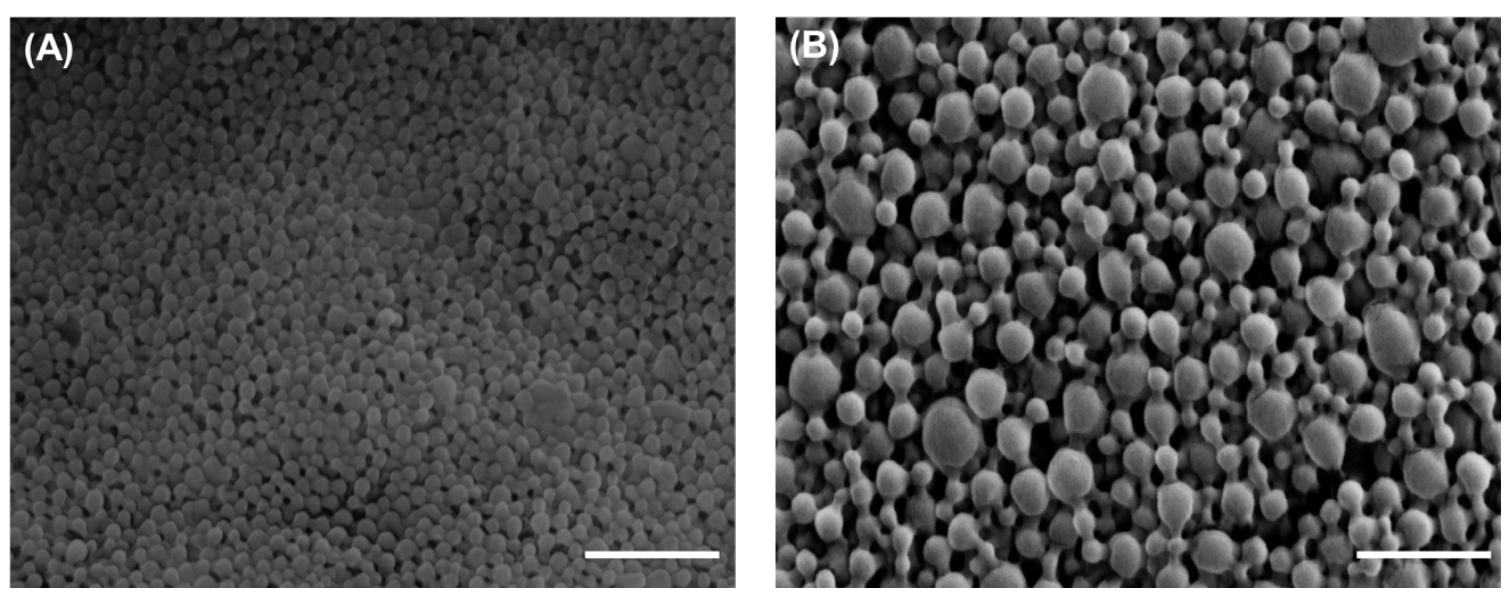

*Figure 12: SEM images of (A) CafA-modified BAR-encapsulated NPs and (B) Unmodified BAR-encapsulated NPS PLGA NPs. Images are representative of a minimum of 3 independent samples, with $n>500$ NPs assessed in total. Scale bar represents $1 \mu \mathrm{m}$.

${ }^{*}$ This data was collected by Mohamed Y. Mahmoud ${ }^{d}$ 


\section{Quantification of ligand surface density}

The concentration of CafA conjugated to the surface of the NP was measured using the microBCA assay. The total protein content ranged from 3 to $36 \mu \mathrm{g} \mathrm{CafA} / \mathrm{mg}$ polymer and varied directly with the input concentration of CafA ( 5 to $80 \mu \mathrm{g}$ CafA/mg polymer) used during synthesis. The conjugation efficiency ranged from 45 to $79 \%$, with higher conjugation efficiency observed at lower concentrations (Figure 13, Table 2). Although saturation was not achieved under these conditions, the results suggest that an increased surface density may be attained with higher CafA input. 


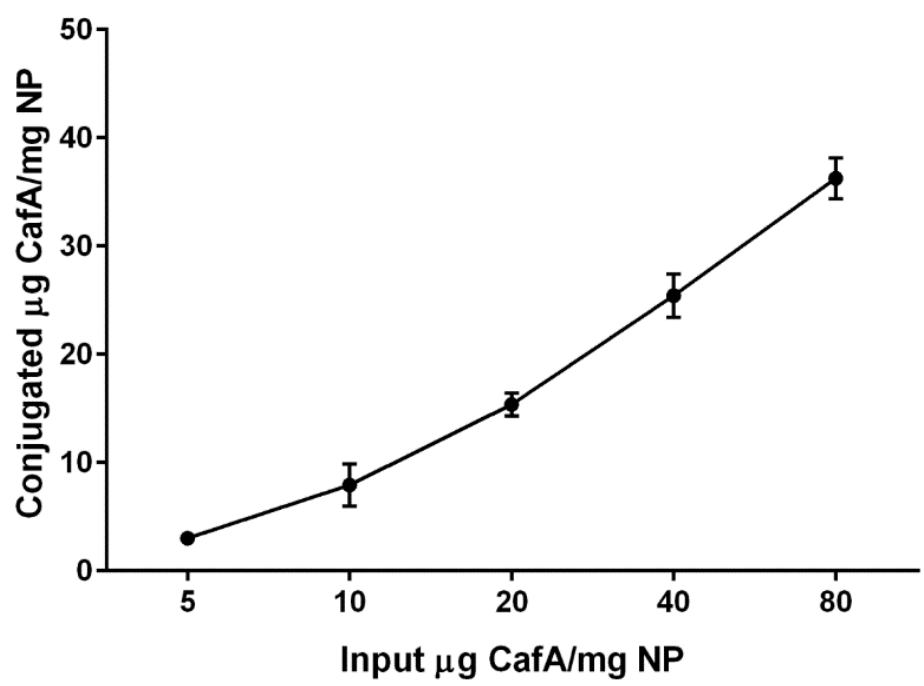

**Figure 13: Quantification of surface density of ligands. The total amount of CafA conjugated to the NP surface was determined using the microBCA assay. The amount of CafA conjugated to the NP surface varied directly with the input concentration of CafA during synthesis. Data represent mean NP associated CafA $\pm S . D, n=3$.

\section{Table 2: Input and output concentration of CafA}

\begin{tabular}{|c|c|c|}
\hline $\begin{array}{c}\text { Input } \\
\text { Concentration } \\
(\mu \mathrm{g} \text { CafA/ mg NP) }\end{array}$ & $\begin{array}{c}\text { Output } \\
\text { Concentration } \\
(\mu \mathrm{g} \text { CafA/ mg NP) }\end{array}$ & $\begin{array}{c}\text { Conjugation } \\
\text { Efficiency (\%) }\end{array}$ \\
\hline 5 & $2.9 \pm 0.1$ & 58 \\
\hline 10 & $7.9 \pm 1.9$ & 79 \\
\hline 20 & $14.4 \pm 2.6$ & 72 \\
\hline 40 & $25.4 \pm 2.2$ & 64 \\
\hline 80 & $36.3 \pm 3.5$ & 45 \\
\hline
\end{tabular}

${ }^{* *}$ Data collected together with Mohamed Y. Mahmoud ${ }^{d}$ 


\section{Loading and release kinetics of BAR peptide from unmodified and CafA-modified NPs}

Nanoparticles modified with an intermediate density of CafA (20 ug/mg polymer) were selected for subsequent characterization and functionality studies, as they represent a practical minimum modification density that in preliminary studies (and results here) provided a therapeutically-relevant concentration of BAR release. To determine the loading of BAR peptide in unmodified and CafA-modified NPs, the amount of F-BAR from dissolved NPs was determined by measuring fluorescence (488/518 nm excitation/emission) and quantified by comparing these values to an F-BAR standard curve. Loading experiments showed that unmodified and CafA-modified NPs encapsulated $16.95 \pm 0.8$ and $15.73 \pm 1.9 \mu \mathrm{g}$ of BAR per mg of NP respectively, corresponding to loading efficiencies of $39 \%$ and $37 \%$ (Table 3 ), suggesting that surface modification at this density had minimal effect on BAR loading.

To measure BAR release, sample eluates were taken 1, 2, 4, 8, and $24 \mathrm{hr}$ after incubation in PBS. The overall release trends showed that CafA-modified NPs demonstrated slower release of BAR, relative to unmodified NPs; however, inhibitory concentrations of BAR peptide ( 2 to $4 \mu \mathrm{g} / \mathrm{mg} \mathrm{NP}$ ) were released from CafA-modified NPs at each of the measured time points up to $8 \mathrm{hr}$. For unmodified NPs, more rapid release profiles were observed, with greater than $50 \%$ of BAR peptide released within $1 \mathrm{hr}$ and a plateau in release after. After 2, 4, 8 and 24 $\mathrm{hr}$, less than $1 \mathrm{\mu g}$ of peptide/mg NP was released from the unmodified NPs (Figure 14), demonstrating inadequate, non-inhibitory levels of release. In comparison, CafA-modified NPs released $23 \%$ of BAR during the first hour, and inhibitory concentrations $(3.1,2.7,2.9$, and $3.3 \mu \mathrm{g} / \mathrm{mg}$ ) of BAR peptide after $2,4,8$, and $24 \mathrm{hr}$. Cumulatively, after $24 \mathrm{hr}$, BAR peptide (15.5 $\mu \mathrm{g} / \mathrm{mg}$ ) was completely released from CafA-modified BAR NPs, whereas $61 \%$ of the encapsulated BAR (10.3 $\mu \mathrm{g} / \mathrm{mg})$ was released from unmodified BAR-encapsulated NPs. Thus, after $24 \mathrm{hr}$, the total quantity of BAR released from CafA-modified NPs was significantly higher than the amount of BAR released from unmodified NPS. 
**Table 3: Encapsulation efficiency of CafA-modified and unmodified NPs.

\begin{tabular}{|c|c|c|c|}
\hline NP Type & $\begin{array}{c}\text { BAR input } \\
(\mu \mathrm{g} / \mathrm{mg})\end{array}$ & $\begin{array}{c}\text { BAR output } \\
(\mu \mathrm{g} / \mathrm{mg})\end{array}$ & $\begin{array}{c}\text { Encapsulation } \\
\text { Efficiency (\%) }\end{array}$ \\
\hline Unmodified NPs & 43 & $16.95 \pm 0.8$ & 39.4 \\
\hline CafA-modified NPs & 43 & $15.73 \pm 1.9$ & 36.5 \\
\hline
\end{tabular}

(A)

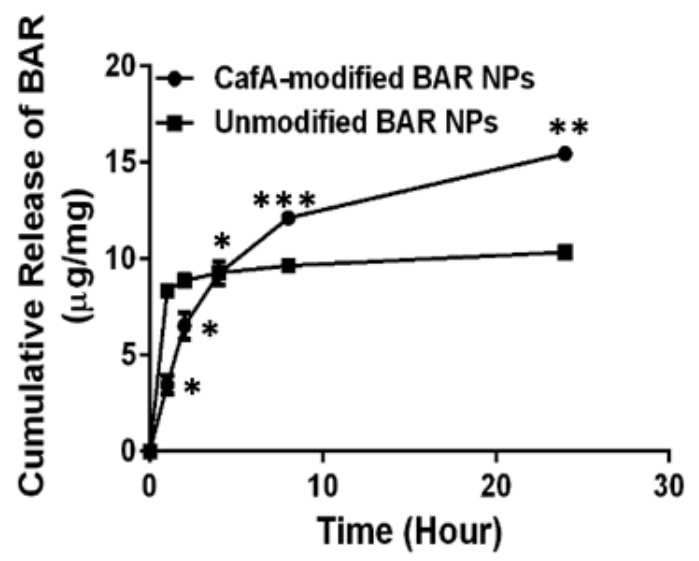

(B)

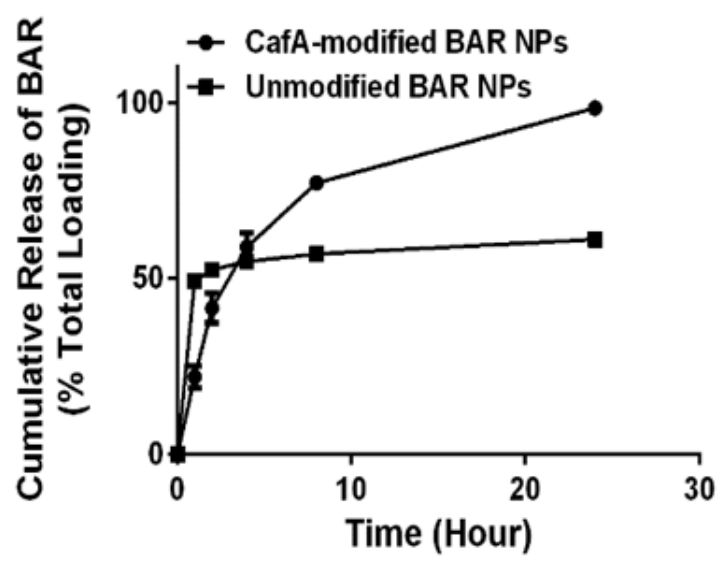

**Figure 14: Release kinetics of BAR peptide from unmodified and CafA-modified NPs Cumulative release of BAR as (A) function of mass ( $\mu$ g BAR per mg NP) and (B) percent of total BAR loaded over $24 \mathrm{hr}$. Asterisks denote a statistically significant difference between two groups $\left({ }^{*} p<0.01,{ }^{* *} p<0.001,{ }^{* * *} p<0.0001,{ }^{* * *} p<0.00001\right)$.

**These data were collected together with Mohamed Y. Mahmoud 


\section{Determination of functionality of surface modification}

Duration of retention of CafA-modified C6 NPs

CafA-modified C6 NPs were incubated with immobilized S. gordonii cells for $1 \mathrm{hr}$, after which unbound NPs were washed and cell-associated fluorescence was measured to determine the amount of NPs that initially bound to $S$. gordonii $(t=0)$. As shown in Figure 15A, after the first hour of binding $(t=0)$, CafA-modified NPs bound to $S$. gordonii at a 2.3-fold higher concentration $(5.7 \mu \mathrm{g} / \mathrm{mL})$, relative to non-specific avidin-modified NPs $(2.5 \mu \mathrm{g} / \mathrm{mL})$. The most significant dissociation of CafA-modified NPs from S. gordonii was observed within $1 \mathrm{hr}$ of assessing initial binding $(t=1)$, after which NP dissociation stabilized for both CafA-modified and avidin-modified NPs. After $8 \mathrm{hr}, 65 \%(3.7 \mu \mathrm{g} / \mathrm{mL})$ of CafA-modified and $56 \%$ of avidinmodified NPs $(1.4 \mu \mathrm{g} / \mathrm{mL})$ remained associated with S. gordonii, resulting in a 2.5 -fold higher concentration of CafA-modified NPs bound to S. gordonii (Figure 15B). These results indicate that the ratio of CafA-modified to avidin-modified NPs bound to S. gordonii was maintained after the first wash and suggest that CafA modification enhances NP retention by increasing the concentration of NPs that initially bind to $S$. gordonii. After $8 \mathrm{hr}$, similar rates of subsequent dissociation resulted in a higher concentration of CafA-modified NPs remaining bound to $S$. gordonii. 
(A)

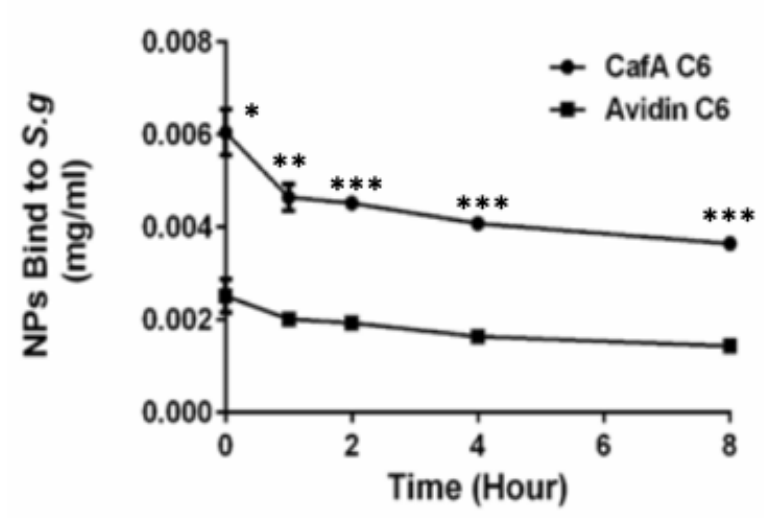

(B)

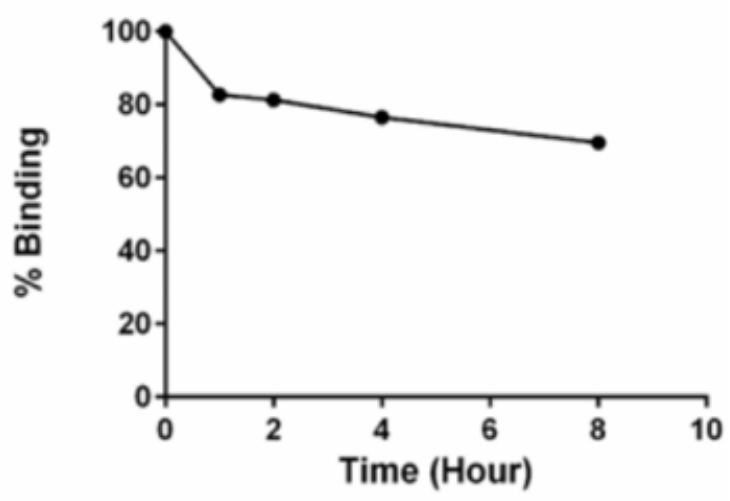

(C)

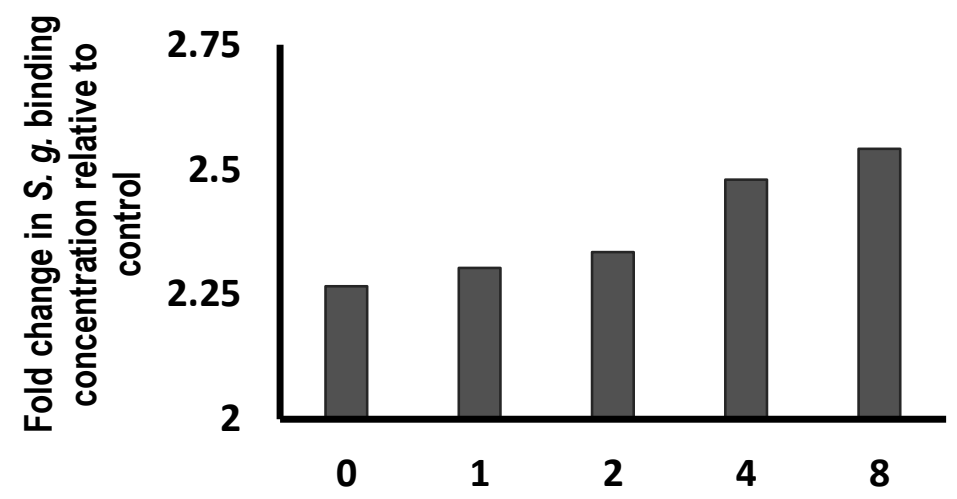

**Figure 15: Duration of retention of CafA-modified C6 NPs. (A) After one hour of initial binding ( $\mathrm{t}=0)$, a 2.3-fold higher concentration of CafA-modified C6 NPs $(5.7 \mathrm{ug} / \mathrm{mL})$ bound to S. g. relative to avidin-modified C6 NPs $(2.5 \mu \mathrm{g} / \mathrm{mL})$ and this difference in concentration was maintained for up to $8 \mathrm{hr}$. (B) $65 \%$ of CafA-modified C6 NPs remain bound to S. $g$. after $8 \mathrm{hr}$. (C) Concentration of CafA-modified NPs bound to S. g. normalized against Avidin-modified NPs. Asterisks denote a statistically significant difference between two groups $\left({ }^{*} p<0.01,{ }^{* *}\right.$ $\left.\mathrm{p}<0.001,{ }^{* * *} \mathrm{p}<0.0001,{ }^{* * *} \mathrm{p}<0.00001\right)$

${ }^{* *}$ Data collected together with Mohamed Y. Mahmoud 


\section{Specificity of adhesion of CafA-modified C6 NPs}

While the overall binding of CafA-modified NPs to $S$. gordonii is important, we sought to assess the differences in CafA-modified NP binding across several bacteria to determine the specificity of NP adhesion. The adherence of CafA-modified NPs to S. gordonii DL-1 was measured relative to S. oralis SO34, S. mutans KPSP2, P. gingivalis ATCC 33277 and A. actinomycetemcomitans 652 cells. For commensal oral streptococci, S. gordonii DL-1 and S. oralis SO34, that express the receptor polysaccharides (RPS), there was no statistical significance in the concentration of bound CafA-modified NPs between groups. For bacterial groups that were RPS-negative, CafA-modified NPs bound to S. gordonii DL-1 at a 1.8-fold higher concentration relative to S. mutans KPSP2 and 2.6-fold higher concentration relative to $P$. gingivalis ATCC 33277 and $A$. actinomycetemcomitans 652 . The concentration of CafAmodified NPs bound to $S$. gordonii DL-1 relative to $S$. mutans KPSP2, P. gingivalis ATCC 33277 and $A$. actinomycetemcomitans 652 was found to be statistically significant $(P \leq 0.05)$. Among non-commensal streptococci, the concentration of CafA-modified NPs bound to S. mutans KPSP2 relative to $P$. gingivalis ATCC 33277 and $A$. actinomycetemcomitans 652 was found to be statistically significant $(P \leq 0.05)$. 


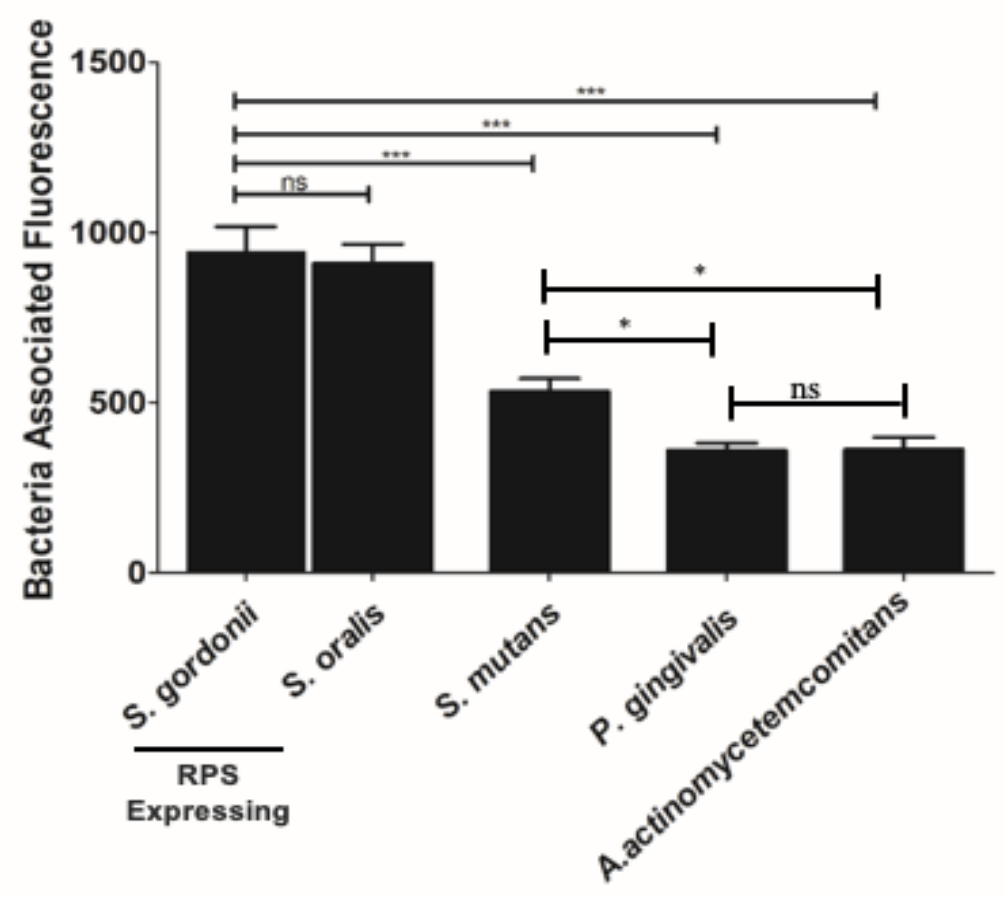

Figure 16: Specificity of CafA-modified C6 NP adhesion. CafA binds the receptor polysaccharides (RPS) found only on commensal oral streptococci such as S. gordonii and S. oralis. It does not bind to bacteria lacking the receptor and therefore, CafA-modified NPs bound to S. gordonii DL-1 (S. g.) and S. oralis SO34 (S. o.) at a higher concentration than S. mutans KPSP2 (S. m.), P. gingivalis ATCC 33277(P. g.), and A.actinomycetemcomitans 652 (A. a.), demonstrating specificity of adherence. Asterisks denote a statistically significant difference between two groups $\left({ }^{*} p<0.01,{ }^{* *} p<0.001,{ }^{* * *} p<0.0001,{ }^{* * * *} p<0.00001\right)$. 


\section{CafA-modified NP-mediated Inhibition of $\boldsymbol{P}$. gingivalis adherence to streptococci}

Functional inhibition assays were performed to determine the impact of CafA-modified BAR NPs on the inhibition of $P$. gingivalis adhesion to S. gordonii. Immobilized S. gordonii were incubated with CafA-modified BAR NPs (treatment group) or CafA-modified blank NPs (control control) for $1 \mathrm{hr}$. After the first hour of binding $(t=0)$ and at each subsequent time point $(\mathrm{t}=2,4,8,12 \mathrm{hr})$ the supernatant containing the unbound NPs and released BAR was removed and $P$. gingivalis was added to the control and treatment plates The plates were incubated for $24 \mathrm{hr}$ and the formed biofilms were visualized using confocal microscopy. Representative images of treatment and control biofilms are shown in Figure 17. At each time point ( $\mathrm{t}=0,2,4,8$ and $12 \mathrm{hr}), P$. gingivalis adherence to $S$. gordonii was significantly reduced in the presence of CafA-modified BAR NPs, relative to control CafA-modified blank NPs (Table 4). After initial administration for one hour $(t=0), P$. gingivalis adherence was inhibited by $87.9 \pm 4.1 \%$ and maintained more than $80 \%$ inhibition after 2 and $4 \mathrm{hr}$, relative to control CafA-modified blank NPs. After 8 and $12 \mathrm{hr}$, time frames relevant to oral administration regimens, $P$. gingivalis binding to $S$. gordonii was inhibited by $66.3 \pm 4.1 \%$ and $40.6 \pm 9.3 \%$, demonstrating the potential of CafA-modified BAR NPs to significantly inhibit $P$. gingivalis adherence to S. gordonii. 

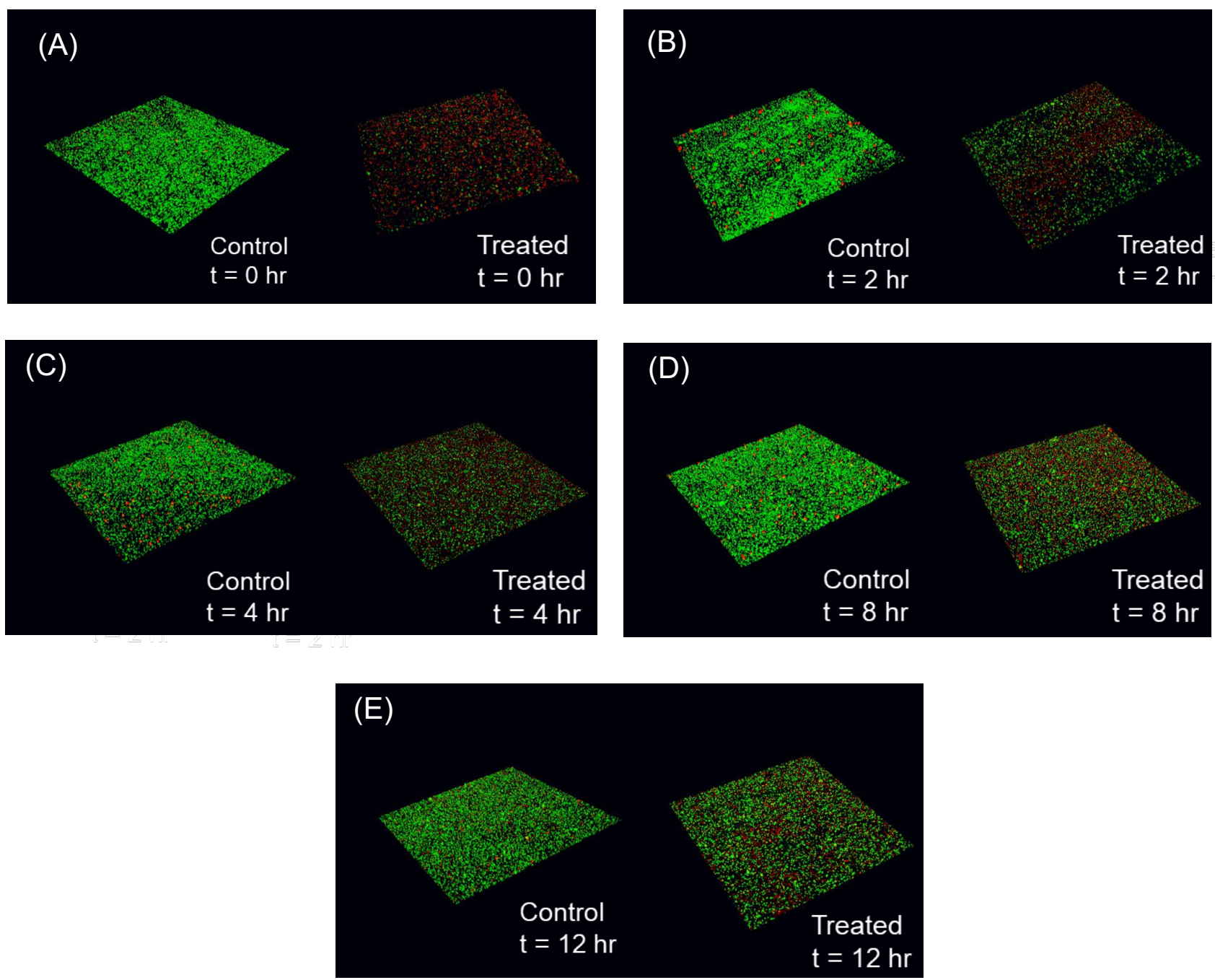

Figure 17(A-E): Functional inhibition assay demonstrating inhibition of $P$. gingivalis adherence to $S$. gordonii. CafA-modified BAR NPs inhibited $P$. gingivalis adherence for more than $8 \mathrm{hr}$ relative to CafA-modified blank NPs (control). Biofilms were visualized using confocal microscopy and the ratio of green $(P . g)$ to red $(S . g$.$) fluorescence in z-stack images was$ determined using Volocity software. 
Table 4: Percent inhibition of $P$. gingivalis adherence to $S$. gordonii at various time points.

\begin{tabular}{|c|c|}
\hline Time Point & Inhibition of $P . g$. Adherence (\%) \\
\hline$t=0 ~ h r$ & $87.9 \pm 4.1$ \\
\hline$t=2 ~ h r$ & $85.5 \pm 2.6$ \\
\hline$t=4 h r$ & $81.4 \pm 9.7$ \\
\hline$t=8 ~ h r$ & $66.3 \pm 4.1$ \\
\hline$t=12 ~ h r$ & $40.6 \pm 9.3$ \\
\hline
\end{tabular}




\section{CHAPTER 5}

\section{DISCUSSION}

The adherence of $P$. gingivalis to $S$. gordonii is a crucial, initial event which facilitates the colonization of $P$. gingivalis in the oral cavity. The binding of $P$. gingivalis to $S$. gordonii is driven by a protein-protein interaction between Mfa1, the structural subunit of the minor fimbriae of $P$. gingivalis, and discrete domains of the streptococcal cell surface protein, $\mathrm{SspB}$, of the antigen I/II family $[125,127,142,143]$. These early interactions provide ideal targets for therapeutic interventions to limit the supragingival colonization of $P$. gingivalis in the oral cavity. Previous studies have shown that a synthetic peptide designated BAR potently inhibits $P$. gingivalis/S. gordonii adherence and reduces the virulence of $P$. gingivalis in a murine model of periodontitis $[67,128,129]$. However, owing to the constant flow of saliva in the oral cavity, free peptide is only transiently retained. Moreover, a higher concentration of free peptide is needed to disrupt pre-established $P$. gingivalis biofilms.

To overcome this challenge, we developed polymeric nanoparticles that encapsulate BAR. BAR-encapsulated NPs $\left(\mathrm{IC}_{50}=0.7 \mu \mathrm{M}\right)$ were found to be more efficacious relative to free peptide $\left(\mathrm{IC}_{50}=1.3 \mu \mathrm{M}\right)$ and inhibited pre-established biofilms potently. However, similar to free peptide, BAR-encapsulated NPs also lack a mechanism by which to prolong retention in the oral cavity. Since BAR-encapsulated NPs release BAR peptide over the course of hours, they may benefit from a strategy to augment their retention in the oral cavity [133]. Given this, the goal of this study was to formulate NPs with improved binding to the GalNAc $\beta 1-3 \mathrm{Gal}$ motif 
of the receptor polysaccharides (RPS) expressed by commensal oral streptococci. In parallel we sought to prolong the release of inhibitory concentrations of BAR peptide for 8 to $12 \mathrm{hr}$, for future application in oral hygiene products, such as oral gels, that are traditionally administered twice daily.

CafA is the tip fimbrillin of type 2 fimbriae of $A$. oris, and during plaque development, it mediates the coaggregation of $A$. oris with commensal oral streptococci. CafA binds to the GalNAcß1-3Gal motif of the RPS found on commensal oral streptococci such as S. gordonii and S. oralis that promote $P$. gingivalis adherence. We hypothesized that functionalization of BAR-encapsulated NPs with CafA would promote the adherence of BAR-encapsulated NPs to oral commensal streptococci such as S. gordonii, indicating future potential in targeting to S. gordonii harboring niches of the oral cavity. Since the S. gordonii/P. gingivalis interaction promotes supragingival $P$. gingivalis colonization, accumulation of BAR-encapsulated NPs and the localized, prolonged release of BAR from this niche may potently inhibit S. gordonii/P. gingivalis biofilm formation and reduce $P$. gingivalis colonization of the oral cavity.

Surface modification of the NPs with ligands such as CafA can be accomplished in two ways; (i) by chemical conjugation or physical adsorption of the ligands on the NP surface after NP formation, or (ii) by linking the ligands to components of the NP (eg: polymer) before formation [144]. Previous studies have shown that the lack of functional groups on the aliphatic polyester backbone of PLGA makes coupling ligands on the surfaces of the nanoparticles particularly challenging. While adsorption of ligands on the surfaces of the NPs is an effective approach for surface modification, there are drawbacks associated with this approach including limited density of surface ligands and decreased targeting effects over time due to desorption of ligands and NP degradation [137]. It has been previously shown that coupling ligands with a lipid (eg: palmitic acid) to form an amphiphilic molecule prior to NP synthesis enhances the density of ligands incorporated into the PLGA matrix and helps to achvieve a stable protein 
coat on NP surfaces $[137,145,146]$. To facilitate a sustained presentation of ligands, we conjugated CafA to palmitic acid prior to its addition during NP synthesis.

Following synthesis, we selected NPs with an intermediate density of surface ligands (20 $\mu \mathrm{g} / \mathrm{mg}$ polymer) for further characterization and functional studies. Although in general, higher ligand density increases binding avidity via multivalent interactions, several studies have reported that NPs with intermediate ligand density exhibit higher binding relative to higher ligand densities [116-118]. Several explanations have been offered for this effect including steric interference; improper ligand orientation which may impede ligand function; or ligand overcrowding, leading to competition between ligands for the same receptor [116-118]. Additionally, these reports have suggested that increasing the ligand density beyond a certain threshold does not improve binding efficiency $[147,148]$. While NPs were formulated with an intermediate CafA concentration, due to the feasibility of using a practical amount of peptide and the satisfactory release properties, these results demonstrate the effectiveness of the formulated NPs in functionality and efficacy. Future studies may focus on improving the efficacy of CafA-modified NPs by tuning ligand surface density to optimize binding efficiency without impeding BAR release kinetics.

While both formulations exhibited high peptide loading, it is well known that polymeric NPs that encapsulate hydrophilic agents demonstrate high burst release due to the entrapment of the encapsulant in the form of small clusters on the surface or within the polymer matrix just below the surface of the particles during synthesis [149]. Studies have shown that surface modification using amphipathic molecules slows the release of the encapsulant from the polymeric NPs $[102,137,149-151]$ due to the increased hydrophobic stabilization and uniform dispersion of the encapsulant in the polymer matrix [152]. Our results were consistent with these findings in that unmodified BAR NPs demonstrated more rapid release corresponding to a burst $(<50 \%$ peptide) within one hour of delivery. We attribute these findings to the 
release of BAR that is adsorbed at, or just underneath the surface of the polymer matrix. After the first hour, minimal additional peptide was released from unmodified NPs. In comparison, CafA-modified NPs demonstrated a more gradual release of BAR peptide over $24 \mathrm{hr}$, likely because to the increased hydrophobic stabilization and uniform dispersion of the peptide within the matrix due to the presence of the Caf-palmitate conjugates on the NP surface. Cumulatively over $24 \mathrm{hr}$, while $61 \%$ of the BAR peptide was released from unmodified NPs, Caf-modified NPs exhibited a near complete release of the BAR peptide. This improved release was likely due to surface modification with hydrophilic ligands, which facilitated the drawing out of a higher amount of BAR peptide from CafA-modified NPs, promoting a complete release of the peptide payload.

In addition to high loading and favorable release kinetics, another desirable characteristic is NP retention at target sites for a prolonged duration. Given the site-specific nature of periodontal disease, local application of therapeutic agents has been found to have better patient acceptance, reduced side-effects and improved clinical outcomes. Although therapeutic agents applied directly to periodontal pockets are effective, they too get drained by the gingival crevicular fluid and saliva flow. Therefore, improving the binding characteristics of delivery vehicles can increase residence time at target sites and enhance NP efficacy. Here we targeted CafA-modified NPs to RPS-expressing bacteria such as S. gordonii, which promote $P$. gingivalis colonization. Our results suggest that CafA-modified NPs demonstrate high binding efficiency and specificity to RPS-expressing commensal bacteria relative to other bacteria including S. mutans, $P$. gingivalis and A.actinomycetemcomitans. Moreover, CafAmodified NPs remained bound to S. gordonii cell surfaces for a prolonged duration (over $8 \mathrm{hr}$ ). Functionally, in a dual-species biofilm, CafA-modified NPs inhibit $P$. gingivalis adherence to S. gordonii potently for up to $8 \mathrm{hr}$. While these results seem promising, future experiments will seek to develop NPs that can be retained at target sites for longer durations (12-24 hr). 
Overall our study suggests that surface modification of NPs with specific biological ligands such as CafA can facilitate NP targeting and adherence to specific receptors on the surfaces of S. gordonii cells for a prolonged duration. Moreover, CafA-modified NPs release inhibitory concentrations of the BAR peptide and potently inhibit $P$. gingivalis adherence to $S$. gordonii for a duration of time relevant to delivery in the oral cavity. CafA-modified NPs represent an efficacious vehicle for targeting BAR peptide to $P$. gingivalis preferred niches.

Future experiments will focus on optimizing the surface density of CafA and evaluating the functionality of these NPs. We anticipate that optimizing the surface density of CafA further will also enhance the retention, drug loading and release kinetics of modified NPs for 12 to 24 hr. In the long term, we hope to apply this work to incorporate CafA-modified NPs into oral gel formulations and test their effectiveness in clinical trials. 


\section{REFERENCES}

1. Eke, P.I., et al., Update on Prevalence of Periodontitis in Adults in the United States: NHANES 2009 to 2012. J Periodontol, 2015. 86(5): p. 611-22.

2. Scannapieco, F.A., Systemic effects of periodontal diseases. Dent Clin North Am, 2005. 49(3): p. 533-50, vi.

3. Hajishengallis, G. and R.J. Lamont, Beyond the red complex and into more complexity: the polymicrobial synergy and dysbiosis (PSD) model of periodontal disease etiology. Mol Oral Microbiol, 2012. 27(6): p. 409-19.

4. Diaz, P.I., L.D. Strausbaugh, and A. Dongari-Bagtzoglou, Fungal-bacterial interactions and their relevance to oral health: linking the clinic and the bench. Front Cell Infect Microbiol, 2014. 4: p. 101.

5. Marsh, P.D. and E. Zaura, Dental biofilm: ecological interactions in health and disease. J Clin Periodontol, 2017. 44 Suppl 18: p. S12-S22.

6. Chandki, R., P. Banthia, and R. Banthia, Biofilms: A microbial home. J Indian Soc Periodontol, 2011. 15(2): p. 111-4.

7. Marsh, P.D., Dental plaque as a microbial biofilm. Caries Res, 2004. 38(3): p. 204-11.

8. Abranches, J., et al., Biology of Oral Streptococci. Microbiol Spectr, 2018. 6(5).

9. Diaz, P.I., et al., Molecular characterization of subject-specific oral microflora during initial colonization of enamel. Appl Environ Microbiol, 2006. 72(4): p. 2837-48.

10. Nyvad, B. and M. Kilian, Microbiology of the early colonization of human enamel and root surfaces in vivo. Scand J Dent Res, 1987. 95(5): p. 369-80.

11. Heim, K.P., et al., Identification of a supramolecular functional architecture of Streptococcus mutans adhesin P1 on the bacterial cell surface. J Biol Chem, 2015. 290(14): p. 9002-19.

12. Takahashi, Y., et al., Identification and characterization of hsa, the gene encoding the sialic acid-binding adhesin of Streptococcus gordonii DL1. Infect Immun, 2002. 70(3): p. 1209-18.

13. Cisar, J.O., et al., Immunochemical and functional studies of Actinomyces viscosus T14V type 1 fimbriae with monoclonal and polyclonal antibodies directed against the fimbrial subunit. J Gen Microbiol, 1991. 137(8): p. 1971-9.

14. Rosan, B. and R.J. Lamont, Dental plaque formation. Microbes Infect, 2000. 2(13): p. 1599-607.

15. Marsh, P.D., Dental plaque as a biofilm and a microbial community - implications for health and disease. BMC Oral Health, 2006. 6 Suppl 1: p. S14.

16. Kolenbrander, P.E., et al., Oral multispecies biofilm development and the key role of cell-cell distance. Nat Rev Microbiol, 2010. 8(7): p. 471-80. 
17. Mazumdar, V., S. Amar, and D. Segre, Metabolic proximity in the order of colonization of a microbial community. PLoS One, 2013. 8(10): p. e77617.

18. Roberts, A.P. and J. Kreth, The impact of horizontal gene transfer on the adaptive ability of the human oral microbiome. Front Cell Infect Microbiol, 2014. 4: p. 124.

19. Huang, R., M. Li, and R.L. Gregory, Bacterial interactions in dental biofilm. Virulence, 2011. 2(5): p. 435-44.

20. Bowen, W.H., et al., Oral Biofilms: Pathogens, Matrix, and Polymicrobial Interactions in Microenvironments. Trends Microbiol, 2018. 26(3): p. 229-242.

21. Flemming, H.C., et al., Biofilms: an emergent form of bacterial life. Nat Rev Microbiol, 2016. 14(9): p. 563-75.

22. Costerton, J.W., P.S. Stewart, and E.P. Greenberg, Bacterial biofilms: a common cause of persistent infections. Science, 1999. 284(5418): p. 1318-22.

23. Stewart, P.S. and J.W. Costerton, Antibiotic resistance of bacteria in biofilms. Lancet, 2001. 358(9276): p. 135-8.

24. Stewart, P.S., A review of experimental measurements of effective diffusive permeabilities and effective diffusion coefficients in biofilms. Biotechnol Bioeng, 1998. 59(3): p. 261-72.

25. Brown, M.R., D.G. Allison, and P. Gilbert, Resistance of bacterial biofilms to antibiotics: a growth-rate related effect? J Antimicrob Chemother, 1988. 22(6): p. 777-80.

26. da Silva-Boghossian, C.M., et al., Association of red complex, $A$. actinomycetemcomitans and non-oral bacteria with periodontal diseases. Arch Oral Biol, 2011. 56(9): p. 899-906.

27. Socransky, S.S., et al., Microbial complexes in subgingival plaque. J Clin Periodontol, 1998. 25(2): p. 134-44.

28. Suzuki, N., M. Yoneda, and T. Hirofuji, Mixed red-complex bacterial infection in periodontitis. Int J Dent, 2013. 2013: p. 587279.

29. Yost, S., et al., Functional signatures of oral dysbiosis during periodontitis progression revealed by microbial metatranscriptome analysis. Genome Med, 2015. 7(1): p. 27.

30. Lamont, R.J., H. Koo, and G. Hajishengallis, The oral microbiota: dynamic communities and host interactions. Nat Rev Microbiol, 2018. 16(12): p. 745-759.

31. Liang, S., et al., The C5a receptor impairs IL-12-dependent clearance of Porphyromonas gingivalis and is required for induction of periodontal bone loss. $\mathrm{J}$ Immunol, 2011. 186(2): p. 869-77.

32. Wang, M., et al., Microbial hijacking of complement-toll-like receptor crosstalk. Sci Signal, 2010. 3(109): p. ra11.

33. Hajishengallis, G., et al., Low-abundance biofilm species orchestrates inflammatory periodontal disease through the commensal microbiota and complement. Cell Host Microbe, 2011. 10(5): p. 497-506.

34. Gaffen, S.L. and G. Hajishengallis, A new inflammatory cytokine on the block: rethinking periodontal disease and the Th1/Th2 paradigm in the context of Th17 cells and IL-17. J Dent Res, 2008. 87(9): p. 817-28.

35. Diaz, P.I., A. Hoare, and B.Y. Hong, Subgingival Microbiome Shifts and Community Dynamics in Periodontal Diseases. J Calif Dent Assoc, 2016. 44(7): p. 421-35.

36. Duran-Pinedo, A.E., et al., Community-wide transcriptome of the oral microbiome in subjects with and without periodontitis. ISME J, 2014. 8(8): p. 1659-72.

37. Hajishengallis, G., The inflammophilic character of the periodontitis-associated microbiota. Mol Oral Microbiol, 2014. 29(6): p. 248-57.

38. Nassar, M., et al., GAS6 is a key homeostatic immunological regulator of hostcommensal interactions in the oral mucosa. Proc Natl Acad Sci U S A, 2017. 114(3): p. E337-E346. 
39. Yost, S., et al., Potassium is a key signal in host-microbiome dysbiosis in periodontitis. PLoS Pathog, 2017. 13(6): p. e1006457.

40. Frias-Lopez, J. and A. Duran-Pinedo, Effect of periodontal pathogens on the metatranscriptome of a healthy multispecies biofilm model. J Bacteriol, 2012. 194(8): p. 2082-95.

41. Non-surgical pocket therapy: mechanical, pharmacotherapeutics, and dental occlusion. J Am Dent Assoc, 1998. 129 Suppl: p. 34S-39S.

42. Guerrero, A., et al., Adjunctive benefits of systemic amoxicillin and metronidazole in non-surgical treatment of generalized aggressive periodontitis: a randomized placebocontrolled clinical trial. J Clin Periodontol, 2005. 32(10): p. 1096-107.

43. Mestnik, M.J., et al., Short-term benefits of the adjunctive use of metronidazole plus amoxicillin in the microbial profile and in the clinical parameters of subjects with generalized aggressive periodontitis. J Clin Periodontol, 2010. 37(4): p. 353-65.

44. Quirynen, M., et al., Topical antiseptics and antibiotics in the initial therapy of chronic adult periodontitis: microbiological aspects. Periodontol 2000, 2002. 28: p. 72-90.

45. Slots, J. and M. Ting, Systemic antibiotics in the treatment of periodontal disease. Periodontol 2000, 2002. 28: p. 106-76.

46. Iqbal, Z., et al., Dental therapeutic systems. Recent Pat Drug Deliv Formul, 2008. 2(1): p. 58-67.

47. Ardila, C.M., M.I. Granada, and I.C. Guzman, Antibiotic resistance of subgingival species in chronic periodontitis patients. J Periodontal Res, 2010. 45(4): p. 557-63.

48. Madianos, P.N., et al., Porphyromonas gingivalis FDC381 multiplies and persists within human oral epithelial cells in vitro. Infect Immun, 1996. 64(2): p. 660-4.

49. Nakhjiri, S.F., et al., Inhibition of epithelial cell apoptosis by Porphyromonas gingivalis. FEMS Microbiol Lett, 2001. 200(2): p. 145-9.

50. Dickinson, B.C., et al., Interaction of oral bacteria with gingival epithelial cell multilayers. Mol Oral Microbiol, 2011. 26(3): p. 210-20.

51. Casarin, R.C., et al., Levels of Aggregatibacter actinomycetemcomitans, Porphyromonas gingivalis, inflammatory cytokines and species-specific immunoglobulin $\mathrm{G}$ in generalized aggressive and chronic periodontitis. J Periodontal Res, 2010. 45(5): p. 635-42.

52. Mahanonda, R., et al., Effect of initial treatment of chronic inflammatory periodontal disease on the frequency of peripheral blood T-lymphocytes specific to periodontopathic bacteria. Oral Microbiol Immunol, 1991. 6(4): p. 221-7.

53. Saini, R., S. Saini, and S. Sharma, Biofilm: A dental microbial infection. J Nat Sci Biol Med, 2011. 2(1): p. 71-5.

54. Burgess, N.A., et al., LuxS-dependent quorum sensing in Porphyromonas gingivalis modulates protease and haemagglutinin activities but is not essential for virulence. Microbiology-Sgm, 2002. 148: p. 763-772.

55. Chung, W.S.O., et al., Signalling system in Porphyromonas gingivalis based on a LuxS protein. Journal of Bacteriology, 2001. 183(13): p. 3903-3909.

56. Reffuveille, F., et al., Staphylococcus aureus Biofilms and their Impact on the Medical Field. 2017.

57. Jang, Y.J., et al., Autoinducer 2 of Fusobacterium nucleatum as a target molecule to inhibit biofilm formation of periodontopathogens. Archives of Oral Biology, 2013. 58(1): p. 17-27.

58. Gerits, E., N. Verstraeten, and J. Michiels, New approaches to combat Porphyromonas gingivalis biofilms. J Oral Microbiol, 2017. 9(1): p. 1300366.

59. Feldman, M. and D. Grenier, Cranberry proanthocyanidins act in synergy with licochalcone A to reduce Porphyromonas gingivalis growth and virulence properties, 
and to suppress cytokine secretion by macrophages. J Appl Microbiol, 2012. 113(2): p. 438-47.

60. Kariu, T., et al., Inhibition of gingipains and Porphyromonas gingivalis growth and biofilm formation by prenyl flavonoids. J Periodontal Res, 2017. 52(1): p. 89-96.

61. Marquis, A., et al., The plant coumarins auraptene and lacinartin as potential multifunctional therapeutic agents for treating periodontal disease. BMC Complement Altern Med, 2012. 12: p. 80.

62. Zasloff, M., Antimicrobial peptides of multicellular organisms. Nature, 2002. 415(6870): p. 389-95.

63. Kamaruzzaman, N.F., et al., Targeting the Bacterial Protective Armour; Challenges and Novel Strategies in the Treatment of Microbial Biofilm. Materials (Basel), 2018. 11(9).

64. Lohan, S. and G.S. Bisht, Recent Approaches in design of Peptidomimetics for Antimicrobial Drug Discovery Resear. Mini Rev Med Chem, 2013.

65. Wakabayashi, H., et al., Inhibitory effects of lactoferrin on growth and biofilm formation of Porphyromonas gingivalis and Prevotella intermedia. Antimicrob Agents Chemother, 2009. 53(8): p. 3308-16.

66. Wang, H.Y., et al., Efficacy of a novel antimicrobial peptide against periodontal pathogens in both planktonic and polymicrobial biofilm states. Acta Biomater, 2015. 25: p. 150-61.

67. Daep, C.A., et al., Structural characterization of peptide-mediated inhibition of Porphyromonas gingivalis biofilm formation. Infect Immun, 2006. 74(10): p. 5756-62.

68. Seo, M.D., et al., Antimicrobial peptides for therapeutic applications: a review. Molecules, 2012. 17(10): p. 12276-86.

69. Patil, P.C., et al., 1,2,3-Triazole-based inhibitors of Porphyromonas gingivalis adherence to oral streptococci and biofilm formation. Bioorg Med Chem, 2016. 24(21): p. 5410-5417.

70. Patil, P.C., et al., 'Second-generation' 1,2,3-triazole-based inhibitors of Porphyromonas gingivalis adherence to oral streptococci and biofilm formation. Medchemcomm, 2019. 10(2): p. 268-279.

71. Tan, J., et al., In Vitro and In Vivo Activity of Peptidomimetic Compounds That Target the Periodontal Pathogen Porphyromonas gingivalis. Antimicrob Agents Chemother, 2018. 62(7).

72. Gupta, A., R.F. Landis, and V.M. Rotello, Nanoparticle-Based Antimicrobials: Surface Functionality is Critical. F1000Res, 2016. 5.

73. Peulen, T.O. and K.J. Wilkinson, Diffusion of nanoparticles in a biofilm. Environ Sci Technol, 2011. 45(8): p. 3367-73.

74. Slomberg, D.L., et al., Role of size and shape on biofilm eradication for nitric oxidereleasing silica nanoparticles. ACS Appl Mater Interfaces, 2013. 5(19): p. 9322-9.

75. $\mathrm{Li}, \mathrm{X}$., et al., Control of nanoparticle penetration into biofilms through surface design. Chem Commun (Camb), 2015. 51(2): p. 282-5.

76. Blecher, K., A. Nasir, and A. Friedman, The growing role of nanotechnology in combating infectious disease. Virulence, 2011. 2(5): p. 395-401.

77. Pelgrift, R.Y. and A.J. Friedman, Nanotechnology as a therapeutic tool to combat microbial resistance. Adv Drug Deliv Rev, 2013. 65(13-14): p. 1803-15.

78. Zhang, L., et al., Development of nanoparticles for antimicrobial drug delivery. Curr Med Chem, 2010. 17(6): p. 585-94.

79. Huang, C.M., et al., Eradication of drug resistant Staphylococcus aureus by liposomal oleic acids. Biomaterials, 2011. 32(1): p. 214-21. 
80. Huh, A.J. and Y.J. Kwon, "Nanoantibiotics": a new paradigm for treating infectious diseases using nanomaterials in the antibiotics resistant era. J Control Release, 2011. 156(2): p. 128-45.

81. Correa, J.M., et al., Silver nanoparticles in dental biomaterials. Int J Biomater, 2015. 2015: p. 485275.

82. Williams, D.N., S.H. Ehrman, and T.R. Pulliam Holoman, Evaluation of the microbial growth response to inorganic nanoparticles. J Nanobiotechnology, 2006. 4: p. 3.

83. Ren, G., et al., Characterisation of copper oxide nanoparticles for antimicrobial applications. Int J Antimicrob Agents, 2009. 33(6): p. 587-90.

84. Muller, R.H., K. Mader, and S. Gohla, Solid lipid nanoparticles (SLN) for controlled drug delivery - a review of the state of the art. Eur J Pharm Biopharm, 2000. 50(1): p. 161-77.

85. Galindo-Rodriguez, S.A., et al., Polymeric nanoparticles for oral delivery of drugs and vaccines: a critical evaluation of in vivo studies. Crit Rev Ther Drug Carrier Syst, 2005. 22(5): p. 419-64.

86. Sanchez-Lopez, E., et al., Metal-Based Nanoparticles as Antimicrobial Agents: An Overview. Nanomaterials (Basel), 2020. 10(2).

87. Karlsson, H.L., et al., Copper oxide nanoparticles are highly toxic: a comparison between metal oxide nanoparticles and carbon nanotubes. Chem Res Toxicol, 2008. 21(9): p. 1726-32.

88. Zupancic, S., et al., Contribution of Nanotechnology to Improved Treatment of Periodontal Disease. Curr Pharm Des, 2015. 21(22): p. 3257-71.

89. Kumari, A., S.K. Yadav, and S.C. Yadav, Biodegradable polymeric nanoparticles based drug delivery systems. Colloids Surf B Biointerfaces, 2010. 75(1): p. 1-18.

90. Wayakanon, K., et al., Polymersome-mediated intracellular delivery of antibiotics to treat Porphyromonas gingivalis-infected oral epithelial cells. FASEB J, 2013. 27(11): p. 4455-65.

91. Liang, J., et al., Emerging Applications of Drug Delivery Systems in Oral Infectious Diseases Prevention and Treatment. Molecules, 2020. 25(3).

92. Horev, B., et al., pH-activated nanoparticles for controlled topical delivery of farnesol to disrupt oral biofilm virulence. ACS Nano, 2015. 9(3): p. 2390-404.

93. Goyal, G., et al., Current nanotechnological strategies for an effective delivery of drugs in treatment of periodontal disease. Crit Rev Ther Drug Carrier Syst, 2014. 31(2): p. 89-119.

94. Kocbek, P., et al., Targeting cancer cells using PLGA nanoparticles surface modified with monoclonal antibody. J Control Release, 2007. 120(1-2): p. 18-26.

95. Zhao, H. and L.Y. Yung, Selectivity of folate conjugated polymer micelles against different tumor cells. Int J Pharm, 2008. 349(1-2): p. 256-68.

96. Acharya, S., F. Dilnawaz, and S.K. Sahoo, Targeted epidermal growth factor receptor nanoparticle bioconjugates for breast cancer therapy. Biomaterials, 2009. 30(29): p. 5737-50.

97. Dhar, S., et al., Targeted delivery of cisplatin to prostate cancer cells by aptamer functionalized Pt(IV) prodrug-PLGA-PEG nanoparticles. Proc Natl Acad Sci U S A, 2008. 105(45): p. 17356-61.

98. Attia, M.F., et al., An overview of active and passive targeting strategies to improve the nanocarriers efficiency to tumour sites. J Pharm Pharmacol, 2019. 71(8): p. 11851198.

99. Cai, X., et al., Chlorhexidine-Loaded Amorphous Calcium Phosphate Nanoparticles for Inhibiting Degradation and Inducing Mineralization of Type I Collagen. ACS Appl Mater Interfaces, 2017. 9(15): p. 12949-12958. 
100. Kilicarslan, M., M. Koerber, and R. Bodmeier, In situ forming implants for the delivery of metronidazole to periodontal pockets: formulation and drug release studies. Drug Dev Ind Pharm, 2014. 40(5): p. 619-24.

101. Endo, K., et al., Tumor-targeted chemotherapy with the nanopolymer-based drug NC6004 for oral squamous cell carcinoma. Cancer Sci, 2013. 104(3): p. 369-74.

102. Kashi, T.S., et al., Improved drug loading and antibacterial activity of minocyclineloaded PLGA nanoparticles prepared by solid/oil/water ion pairing method. Int J Nanomedicine, 2012. 7: p. 221-34.

103. Nafee, N.A., et al., Mucoadhesive buccal patches of miconazole nitrate: in vitro/in vivo performance and effect of ageing. Int J Pharm, 2003. 264(1-2): p. 1-14.

104. Diaz del Consuelo, l., et al., Ex vivo evaluation of bioadhesive films for buccal delivery of fentanyl. J Control Release, 2007. 122(2): p. 135-40.

105. Rosenblum, D., et al., Progress and challenges towards targeted delivery of cancer therapeutics. Nat Commun, 2018. 9(1): p. 1410.

106. TM, M.W., W.M. Lau, and V.V. Khutoryanskiy, Chitosan and Its Derivatives for Application in Mucoadhesive Drug Delivery Systems. Polymers (Basel), 2018. 10(3).

107. $\mathrm{Cu}, \mathrm{Y}$., et al., Ligand-modified gene carriers increased uptake in target cells but reduced DNA release and transfection efficiency. Nanomedicine, 2010. 6(2): p. 33443.

108. Yin, Y., et al., Lectin-conjugated PLGA nanoparticles loaded with thymopentin: ex vivo bioadhesion and in vivo biodistribution. J Control Release, 2007. 123(1): p. 27-38.

109. Zhang, N., et al., PLGA nanoparticle--peptide conjugate effectively targets intercellular cell-adhesion molecule-1. Bioconjug Chem, 2008. 19(1): p. 145-52.

110. Jiang, Z., et al., Peptide ligand-mediated targeted drug delivery of nanomedicines. Biomater Sci, 2019. 7(2): p. 461-471.

111. Marques, A.C., et al., Functionalizing nanoparticles with cancer-targeting antibodies: A comparison of strategies. J Control Release, 2020. 320: p. 180-200.

112. Saboktakin, M.R., et al., Development and in vitro evaluation of thiolated chitosan-Poly(methacrylic acid) nanoparticles as a local mucoadhesive delivery system. Int J Biol Macromol, 2011. 48(3): p. 403-7.

113. Lee, B.S., et al., Controlled-release of tetracycline and lovastatin by poly(D,L-lactideco-glycolide acid)-chitosan nanoparticles enhances periodontal regeneration in dogs. Int J Nanomedicine, 2016. 11: p. 285-97.

114. Yao, W., et al., RGD functionalized polymeric nanoparticles targeting periodontitis epithelial cells for the enhanced treatment of periodontitis in dogs. J Colloid Interface Sci, 2015. 458: p. 14-21.

115. Mahmoud, M.Y., J.M. Steinbach-Rankins, and D.R. Demuth, Functional assessment of peptide-modified PLGA nanoparticles against oral biofilms in a murine model of periodontitis. J Control Release, 2019. 297: p. 3-13.

116. Nanoparticle targeting of Gram-positive and Gram-negative bacteria for magneticbased separations of bacterial pathogens.

117. Cheng, Z., et al., Multifunctional nanoparticles: cost versus benefit of adding targeting and imaging capabilities. Science, 2012. 338(6109): p. 903-10.

118. Elias, D.R., et al., Effect of ligand density, receptor density, and nanoparticle size on cell targeting. Nanomedicine, 2013. 9(2): p. 194-201.

119. Colombo, M., et al., Tumour homing and therapeutic effect of colloidal nanoparticles depend on the number of attached antibodies. Nat Commun, 2016. 7: p. 13818.

120. How, K.Y., K.P. Song, and K.G. Chan, Porphyromonas gingivalis: An Overview of Periodontopathic Pathogen below the Gum Line. Front Microbiol, 2016. 7: p. 53. 
121. Daep, C.A., et al., Selective substitution of amino acids limits proteolytic cleavage and improves the bioactivity of an anti-biofilm peptide that targets the periodontal pathogen, Porphyromonas gingivalis. Peptides, 2010. 31(12): p. 2173-8.

122. Chung, W.O., D.R. Demuth, and R.J. Lamont, Identification of a Porphyromonas gingivalis receptor for the Streptococcus gordonii SspB protein. Infect Immun, 2000. 68(12): p. 6758-62.

123. Maeda, K., et al., Characterization of binding of Streptococcus oralis glyceraldehyde3-phosphate dehydrogenase to Porphyromonas gingivalis major fimbriae. Infect Immun, 2004. 72(9): p. 5475-7.

124. Sojar, H.T. and R.J. Genco, Identification of glyceraldehyde-3-phosphate dehydrogenase of epithelial cells as a second molecule that binds to Porphyromonas gingivalis fimbriae. FEMS Immunol Med Microbiol, 2005. 45(1): p. 25-30.

125. Park, Y., et al., Short fimbriae of Porphyromonas gingivalis and their role in coadhesion with Streptococcus gordonii. Infect Immun, 2005. 73(7): p. 3983-9.

126. Brooks, W., et al., Identification of a Streptococcus gordonii SspB domain that mediates adhesion to Porphyromonas gingivalis. Infect Immun, 1997. 65(9): p. 37538.

127. Demuth, D.R., et al., Discrete protein determinant directs the species-specific adherence of Porphyromonas gingivalis to oral streptococci. Infect Immun, 2001. 69(9): p. 5736-41.

128. Daep, C.A., R.J. Lamont, and D.R. Demuth, Interaction of Porphyromonas gingivalis with oral streptococci requires a motif that resembles the eukaryotic nuclear receptor box protein-protein interaction domain. Infect Immun, 2008. 76(7): p. 3273-80.

129. Daep, C.A., et al., Structural dissection and in vivo effectiveness of a peptide inhibitor of Porphyromonas gingivalis adherence to Streptococcus gordonii. Infect Immun, 2011. 79(1): p. 67-74.

130. Chawla, A., et al., Community signalling between Streptococcus gordonii and Porphyromonas gingivalis is controlled by the transcriptional regulator CdhR. Mol Microbiol, 2010. 78(6): p. 1510-22.

131. Kuboniwa, M., et al., Metabolic crosstalk regulates Porphyromonas gingivalis colonization and virulence during oral polymicrobial infection. Nat Microbiol, 2017. 2(11): p. 1493-1499.

132. McNab, R., et al., LuxS-based signalling in Streptococcus gordonii: autoinducer 2 controls carbohydrate metabolism and biofilm formation with Porphyromonas gingivalis. J Bacteriol, 2003. 185(1): p. 274-84.

133. Mahmoud, M.Y., D.R. Demuth, and J.M. Steinbach-Rankins, BAR-encapsulated nanoparticles for the inhibition and disruption of Porphyromonas gingivalisStreptococcus gordonii biofilms. J Nanobiotechnology, 2018. 16(1): p. 69.

134. Wang, L.S., A. Gupta, and V.M. Rotello, Nanomaterials for the Treatment of Bacterial Biofilms. ACS Infect Dis, 2016. 2(1): p. 3-4.

135. Wu, C., et al., Dual function of a tip fimbrillin of Actinomyces in fimbrial assembly and receptor binding. J Bacteriol, 2011. 193(13): p. 3197-206.

136. Reardon-Robinson, M.E., et al., Pilus hijacking by a bacterial coaggregation factor critical for oral biofilm development. Proc Natl Acad Sci U S A, 2014. 111(10): p. 383540.

137. Fahmy, T.M., et al., Surface modification of biodegradable polyesters with fatty acid conjugates for improved drug targeting. Biomaterials, 2005. 26(28): p. 5727-36.

138. Steinbach, J.M., Protein and oligonucleotide delivery systems for vaginal microbicides against viral STIs. Cell Mol Life Sci, 2015. 72(3): p. 469-503.

139. Steinbach, J.M., et al., Polymer nanoparticles encapsulating siRNA for treatment of HSV-2 genital infection. J Control Release, 2012. 162(1): p. 102-10. 
140. Sims, L.B., et al., Enhanced uptake and transport of PLGA-modified nanoparticles in cervical cancer. J Nanobiotechnology, 2016. 14: p. 33.

141. Steinbach, J.M., Y.E. Seo, and W.M. Saltzman, Cell penetrating peptide-modified poly(lactic-co-glycolic acid) nanoparticles with enhanced cell internalization. Acta Biomater, 2016. 30: p. 49-61.

142. Cook, G.S., J.W. Costerton, and R.J. Lamont, Biofilm formation by Porphyromonas gingivalis and Streptococcus gordonii. J Periodontal Res, 1998. 33(6): p. 323-7.

143. Lamont, R.J., et al., Role of the Streptococcus gordonii SspB protein in the development of Porphyromonas gingivalis biofilms on streptococcal substrates. Microbiology, 2002. 148(Pt 6): p. 1627-36.

144. Yoo, J., et al., Active Targeting Strategies Using Biological Ligands for Nanoparticle Drug Delivery Systems. Cancers (Basel), 2019. 11(5).

145. $\mathrm{Cu}, \mathrm{Y}$. and W.M. Saltzman, Controlled surface modification with poly(ethylene)glycol enhances diffusion of PLGA nanoparticles in human cervical mucus. Mol Pharm, 2009. 6(1): p. 173-81.

146. Park, J., et al., PEGylated PLGA nanoparticles for the improved delivery of doxorubicin. Nanomedicine, 2009. 5(4): p. 410-8.

147. Liu, J., et al., Computational model for nanocarrier binding to endothelium validated using in vivo, in vitro, and atomic force microscopy experiments. Proc Natl Acad Sci U S A, 2010. 107(38): p. 16530-5.

148. Zhou, Y., et al., Impact of single-chain Fv antibody fragment affinity on nanoparticle targeting of epidermal growth factor receptor-expressing tumor cells. J Mol Biol, 2007. 371(4): p. 934-47.

149. Thote, A.J. and R.B. Gupta, Formation of nanoparticles of a hydrophilic drug using supercritical carbon dioxide and microencapsulation for sustained release. Nanomedicine, 2005. 1(1): p. 85-90.

150. Mu, L. and S.S. Feng, Vitamin E TPGS used as emulsifier in the solvent evaporation/extraction technique for fabrication of polymeric nanospheres for controlled release of paclitaxel (Taxol). J Control Release, 2002. 80(1-3): p. 129-44.

151. $\mathrm{Mu}, \mathrm{L}$. and S.S. Feng, A novel controlled release formulation for the anticancer drug paclitaxel (Taxol): PLGA nanoparticles containing vitamin E TPGS. J Control Release, 2003. 86(1): p. 33-48.

152. Thomasin, C., et al., Drug microencapsulation by PLA/PLGA coacervation in the light of thermodynamics. 1. Overview and theoretical considerations. J Pharm Sci, 1998. 87(3): p. 259-68. 
Name: Hetal Desai

\section{Education:}

University of California, Los Angeles

Doctor of Dental Surgery (D.D.S)

2009-2011

Nair Hospital Dental College

Bachelor of Dental Surgery (B.D.S)

2001-2006

\section{Presentations:}

Research! Louisville Sept 2019

Poster: Functionalizing nanoparticles with CafA protein to target BAR peptide for oral delivery application.

Hinman Student Symposium, Nov 2019

Poster: Functionalizing nanoparticles with CafA protein to target BAR peptide for oral delivery applications.

IADR, March 2020

Poster published in special issue of the Journal of Dental Research. Title: Functionalizing nanoparticles with CafA protein to target BAR peptide for oral delivery applications. 